Portland State University

PDXScholar

7-8-1994

\title{
The Particular Nature of Long-term Lesbian Relationships
}

Karen Marie Freeman

Portland State University

Follow this and additional works at: https://pdxscholar.library.pdx.edu/open_access_etds

Part of the Sociology Commons

Let us know how access to this document benefits you.

\section{Recommended Citation}

Freeman, Karen Marie, "The Particular Nature of Long-term Lesbian Relationships" (1994). Dissertations and Theses. Paper 4797.

https://doi.org/10.15760/etd.6680

This Thesis is brought to you for free and open access. It has been accepted for inclusion in Dissertations and Theses by an authorized administrator of PDXScholar. Please contact us if we can make this document more accessible: pdxscholar@pdx.edu. 


\section{THESIS APPROVAL}

The abstract and thesis of Karen Marie Freeman for the Master of Science in Sociology were presented July 8, 1994, and accepted by the thesis committee and the department.

COMMITTEE APPROVALS:
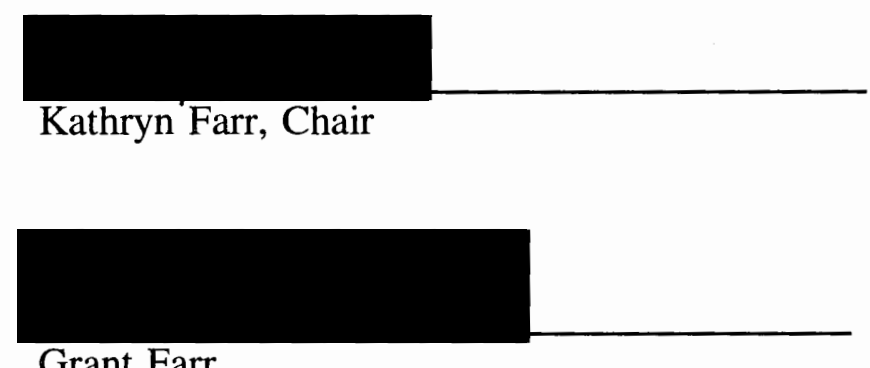

Grant Farr
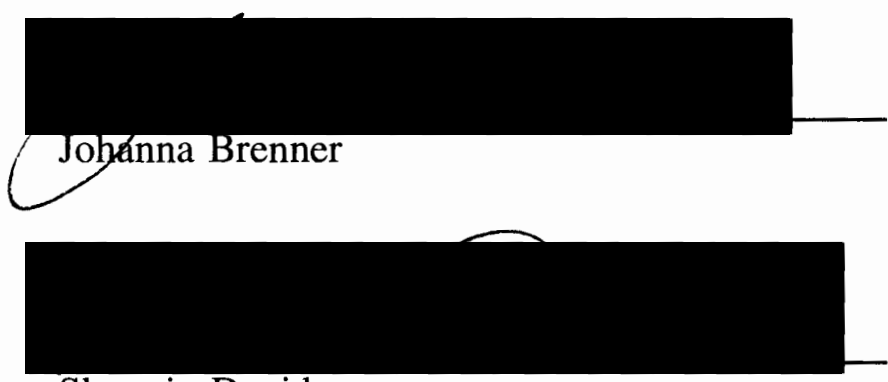

Sherwin Davidson

Representative of the Office of Gradyara Studies

DEPARTMENTAL APPROVAL:

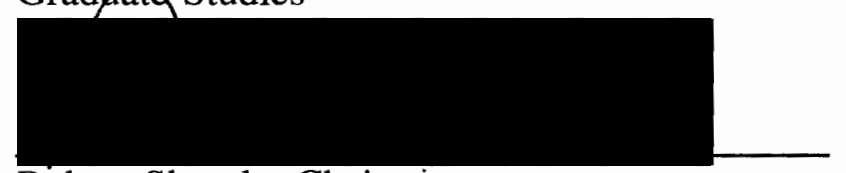

Robert Shotola, Chair

Department of Sociology

$* * * * * * * * * * * * * * * * * * * * * * * * * * * * * * * * * * * * * * * * * * * * * * * * * * * * * * * * * * * * * * * * * * * * * *$

ACCEPTED FOR PORTLAND STATE UNIVERSITY BY THE LIBRARY

By

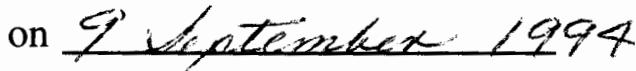




\begin{abstract}
An abstract of the thesis of Karen Marie Freeman for the Master of Science in Sociology presented July 8, 1994.
\end{abstract}

Title: The Particular Nature of Long-Term Lesbian Relationships

The purpose of this thesis was to examine the characteristics of long-term lesbian relationships (operationally defined as five or more years) and to compare these characteristics with prior findings on short-term or term non-specific lesbian relationships. Several studies that have been done made assumptions about the nature of lesbian relationships based on data gathered from women in brief relationships (Caldwell and Peplau 1984; Elise 1986; Gordon 1980; Krestan and Bepko 1980). This study was designed to examine whether or not lesbians in long-term relationships might have different interpersonal relational dynamics, just as married heterosexual couples have been shown to have relationships differing from heterosexual cohabitating couples.

A questionnaire was developed by taking questions directly from prior studies on lesbian relationships in order to allow for direct comparisons. The specific areas investigated were power and equality, merger, feminist impact, structural supports and sexuality. The study used a non-random sample. The fifty-three couples who 
participated were gathered from announcements made at local and national lesbian events. The data were analyzed through tabular and correlational procedures.

Many of the findings in this study were similar to those of earlier research. The respondents were just as likely as those in prior studies to be feminists, to value both autonomy and relatedness, to be sexually satisfied, and to have similar attitudes about women's issues. Feminism, and its focus on independence and non-monogamy, does not seem to have affected these women's abilities to maintain a long-term relationship. But the differences are also important to note. Prior studies had indicated that having equality with their partner was essential for lesbians within their relationships, and couples in this study were much more likely than those in prior studies to say that they had an equal balance of power. They were also more committed. They were more willing to move for their partner, buy a home or car with their partner, and much more likely to believe that they would still be together five years later. They were more likely to have made large joint financial commitments together and to have pooled finances.

This information is important for lesbians who value long-term commitments, for therapists who may be assisting lesbian clientele with their relational dynamics, and for researchers examining lesbian relationships. 
THE PARTICULAR NATURE OF LONG-TERM LESBIAN RELATIONSHIPS

By

KAREN MARIE FREEMAN

A thesis submitted in partial fulfillment of the

requirements for the degree of

\section{MASTER OF SCIENCE \\ in SOCIOLOGY}

Portland State University

1994 


\section{TABLE OF CONTENTS}
Abstract
p. ii - iii

Chapter I

Introduction

p. $2-5$

Chapter II

Prior Work/ Theoretical Perspectives

p. $6-24$

Chapter III

Methodology

p. $25-33$

Chapter IV

Findings

p. $34-51$

Chapter V

Conclusion

p. $52-60$

Bibliography

p. $61-63$

Appendix: questionnaire

p. $64-75$ 


\section{CHAPTER I}

\section{INTRODUCTION}

Much has been written about heterosexual relationships, but until quite recently there has been little available on lesbian relationships. Most of the work that has been done has focused only on specific aspects of that relationship and/or has surveyed primarily women in shorter term relationships (Cotton 1975; Blumstein and Schwartz 1983; Gordon 1980; Peplau et al. 1978, 1984, 1986). Specifically, what is missing in the literature is information about relational dynamics among lesbians in long term relationships.

In heterosexual relationships, the ritual of marriage serves as a marker of commitment and intention. Studies have shown that there are significant relational differences between heterosexual co-habitating couples and those who are married (see Blumstein and Schwartz 1983). It is likewise reasonable to expect differences in the relational dynamics between those lesbians in more casual relationships and those more committed. As there is currently no marker such as institutional marriage in the lesbian community to determine intention and commitment, longevity of relationship may be the best indicator.

Studies that have been done make assumptions and predictions about the nature of lesbian relationships from data based primarily on shorter-term relationships (Blumstein and Schwartz 1983; Caldwell and Peplau 1984; Gordon 1980; Krestan and Bepko 1980; Peplau et al. 1978). Using a sample of lesbians in longer-term 
relationships, this study compares these findings with those of previous researchers (Blumstein and Schwartz 1983; Caldwell and Peplau 1984; Cotton 1975; Falbo and Peplau 1980; Gordon 1980; Peplau et al. 1978; Peplau et al. 1982).

The present study examines four perspectives on lesbian relationships as well as the issue of lesbian sexuality. The first perspective focuses on power and equality and relies heavily on social exchange theory for predictions regarding the distribution of power. From this perspective several researchers have examined the nature of power dynamics in lesbian relationships (Caldwell and Peplau 1984; Falbo and Peplau 1980; Peplau et al. 1987), including associations between power and equality, fusion, autonomy and personal resources. While this body of data is informative, much of it comes from respondents who had been in a relationship less than two years. This study builds on some of the earlier research on power dynamics but with a population of lesbians in longer term relationships. In the present study the resources of each partner were examined to determine if the balance of power or lack thereof was related to the distribution of those resources.

The second perspective focuses on issues of enmeshment/fusion (a lack of clear personal individual boundaries within the relationship) and its relation to sex role socialization. One researcher (Cotton 1975) claimed that lesbian relationships often broke up in three to four years due to a tendency toward psychological enmeshment and a concomitant decrease in the freedom and independence of the two partners. Women's socialization to be relational rather than self-focused was thought to be associated with a subsequent decrease in individual freedom in lesbian relationships, and a major contributing factor to relationship termination. If this were true, then would lesbians in long term relationships be women who did not have problems with fusion?

A third perspective argues that feminism may be another cause of lesbian 
relationship dissolution. Critics of feminism have speculated that the feminist emphasis on independence and autonomy, as well as support for non-monogamy, might diminish women's abilities or interest in investing in a long-term partner relationship. If this were true, one would expect to find lower levels of feminism in a population of lesbians in long-term relationships. It has been suggested by others (Blumstein and Schwartz, 1983; Peplau et al. 1987), however, that autonomy and independence are traits that may in fact strengthen a woman's ability to be in a healthy relationship. And while a healthy relationship is not necessarily defined by longevity, relational skills might better allow for the possibility of a long term commitment. One could hypothesize that lesbians who chose to have longer term relationships would be most likely to succeed it they possessed both relational skills and personal autonomy.

Another perspective, best articulated by Blumstein and Schwartz (1983), theorizes that a lack of structural support creates great difficulties for lesbians attempting to create and sustain long term relationships. Blumstein and Schwartz argued that lesbians who have created structural supports early in their relationships that mimic those more automatically available to heteosexual married couples, might be the most likely to survive- that lesbians who, early in their relationship, were able to have joint finances, wills, trusts, joint purchases of furniture, cars, etc. would be more likely to have relationship longevity. It is also possible that these support structures and mutual entanglements might simply reflect strong commitment to permanence in the relationship, or that the accumulation of the above mentioned bonds might be a result of, rather than a contributing factor to, relationship longevity.

An additional factor often mentioned in lesbian research is sexuality. The findings about lesbian sexuality, however, have been inconsistent. Several early studies (Cotton 1975; Tripp 1975) concluded that lesbians often stopped having sex after the first three years of the relationship while more recent studies (Blumstein and 
Schwartz 1983, Loulan 1987) found that the majority of lesbians in relationships lasting between two and ten years had sex at least once a month. In this same study, lesbians reported that sexuality was very important to them, while in another (Gordon 1980), most lesbians said they would not leave their relationship if sex stopped altogether. In the present study I included questions regarding sexual frequency, satisfaction and importance and attempted to determine the relationship between sexual frequency and satisfaction and measures of fusion, power, and "outness" (how open a person is about her homosexuality).

The current study was undertaken in order to examine the specific dynamics of long-term lesbian relationships and to examine whether or not findings from prior research on shorter-term relationships would be applicable to longer-term relationships. Fifty-three lesbian couples in long-term relationships (defined as five or more years) participated in the study. Questions used to examine the qualities of long-term relationships were adapted from prior studies (Blumstein and Schwartz 1983; Peplau et al., 1978; Peplau et al., 1982). Potential respondents were identified through a snowball sampling process generated through public notices, announcements at lesbian events, acquaintances of mine and acquaintances of the respondents. The data were analyzed using tabular and correlational procedures. 


\section{CHAPTER II}

\section{PRIOR WORK AND THEORETICAL PERSPECTIVES}

\section{$\underline{\text { Specific Relevant Studies }}$}

The present study relied heavily for methodology and substance on the studies described below. Additionally, the four perspectives previously described and further elaborated on in this chapter were gleaned from these and other works.

Dahlstrom (1989)

In this research the author examined "positive" and "negative" sex role traits/personal attributes and their relation to psychological merger (operationally defined as "ego diffusion and a high degree of interpersonal dependency") within lesbian relationships. Thirty-eight couples participated in the study. They had been together at least a year, with the current relationship averaging six years. The couples were largely white, well educated, and middle income.

Peplau, Cochran, Rook and Padesky (1987)

The authors' research focused primarily on differences in relationship values among lesbians, specifically how the women scored on measures of dyadic attachment ("an emphasis on establishing emotionally close and relatively secure love relationships" (p.8)) and personal autonomy ("emphasis on independence and selfactualization that may lead to a questioning of traditional patterns of love relationship"(p.8)). The scores were correlated with feminism, relationship satisfaction, future commitment, monogamy and problems with independence. The sample consisted 
of one hundred twenty-seven lesbians in Los Angeles, California. The women were primarily white and well educated, with the median length of their longest relationship being two and a half years.

Krestan and Bepko (1980)

The authors, both specialists in family therapy, took a systems approach to the development of hypotheses about the problems of co-dependency and fusion within lesbian relationships. They examined internal and external relationship stressors in order to better define fusion in lesbian relationships within the context of societal, family and sex-role socialization constraints. They also examined differentiation and autonomy within relationships, closed systems and subsystems within the culture, and the effects of sexism and homophobia on relationships. They then offered new interpretations of the data based on psychological theory and private client observations.

Caldwell and Peplau (1984)

The authors examined power in lesbian relationships as it was related to income, education, commitment, feminism, and relationship satisfaction. Specifically, the study was an examination of the intricacies of the balance of power within a lesbian relationship, particularly as they reflected social exchanges and the effect of personal resources. The sample consisted of seventy-seven lesbians living in the Los Angeles area who were currently involved in a relationship. The sample was highly educated, middle income, and white, with a median age of 27. 
Blumstein and Schwartz (1983)

Blumstein and Schwartz collaborated on an extensive study examining the structure and dynamics of American couples. Specifically, they focused on the areas of money, sex, and work, in their efforts to describe how American relationships were responding to current cultural and ideological changes. Six thousand couples participated in the research: approximately 4,000 of the couples were heterosexual married, or heterosexual cohabitating, nearly 1,000 were gay male couples, and 788 couples were lesbian. Of the lesbians surveyed, nearly half had been together two years or less and $78 \%$ had been together five years or less. Overall, the lesbians were highly educated, had an average income lower than those of the other groups, were primarily "out", and were between the ages of twenty and forty.

Peplau, Padasky and Hamilton (1982)

This study examined the association between satisfaction in lesbian relationships and power, equality, involvement, similarity between partners, and level of commitment. Associations between relationship satisfaction and personal characteristics such as age, education and "outness" were also studied. The sample of one hundred and twenty lesbians was typically highly educated, middle income, white, under 30 years of age, and from the Los Angeles area. The median length of these women's relationships was 13 months.

Falbo and Peplau (1980)

This research examined the power strategies used by heterosexual and homosexual men and women in their intimate relationships. The study focused on the couple's romantic/sexual relationship as it related to power, independence, autonomy, 
and commitment. Four test groups were created for a total of two hundred participants: fifty each of heterosexual men, heterosexual women, lesbians and gay men. The lesbians in this study had a mean age of twenty-three and a half and had been in their relationship approximately twenty months.

\section{THEORETICAL PERSPECTIVES}

\section{$\underline{\text { Power and Equality in Social Exchange }}$}

According to social exchange theory, a relationship involves a set of costs and rewards. To the extent that the rewards are greater than the cost, participant satisfaction with the relationship will be high. Social exchange theory predicts that power in a relationship will favor the partner who has the greater personal resources. Personal resources have most often been thought of as education, money, or status, but may include "anything that one partner may make available to the other, helping the latter satisfy his [sic] needs or attain his goals" (Blood and Wolfe 1960, p.12). The theory also argues that the person with greater dependence on the relationship will have less power. Waller (1938) call this the "principle of least interest".

Social exchange theory predicts that "the relative balance of involvement or commitment in a relationship affects satisfaction (and that) only when two lovers' affection for and commitment to one another expand at roughly the same pace do they tend mutually to reinforce their love"(Blau 1964, p.84). Social exchange theory, and the more recent interdependence theory (Kurdeck and Schmidt 1992; Rusbult 1983), which proposes that "relationship stability is related to high satisfaction with the relationship, few attractive alternatives to the relationship, and a large investment in the relationship" (Kurdek and Schmidt 1986 p.711), both deal with the importance of 
having a balance of power in all relationships. In lesbian relationships, however, the importance of equality seems to take on an extra emphasis.

A number of researchers have found that lesbians consistently endorse the ideal of an equal power relationship and clearly dislike the idea of either partner having dominance; however, within lesbian relationships there are still a number of women who do not experience the equality they espouse (see, Barnhart 1975; Blumstein and Schwartz 1983; Caldwell and Peplau 1984; Peplau, Padasky and Hamilton 1982; Wolf 1979). Explanations of power imbalance and its effects on the relationship have varied.

For example, Blumstein and Schwartz looked at power primarily as it related to finances. They defined power simply as "the ability to get one's way, to influence important decisions." In their research they found that the primary way that most people achieved power in their relationships was through the control of money. They found that this was true for all types of couples except lesbians. In lesbian relationships financial imbalance (and the resulting power imbalance) was often experienced as disturbing, and partners would go to great lengths to rebalance the situation. The authors' assumption was that women have been acculturated to financial dependence on men in relationships, and that as lesbians they find this a dynamic they would like to avoid. In fact, they noted that of all the couples they surveyed, lesbians placed the greatest value on self-sufficiency.

Another finding from the Blumstein and Schwartz research was that all couples, except lesbians, who were unhappy about the amount of money in the relationship, were also less satisfied with their relationship. The authors theorized that one reason that money concerns might affect lesbians less was that women in our culture who are not attached to men are more accustomed to being poor. Because of this experience 
lesbians may have few expectations of a partner's financial status other than that she can support herself.

Blumstein and Schwartz concluded the following about the lesbians in their study: they tended to be relationship centered and personally independent; they tried to avoid having one partner dependent on the other; they strongly desired partners who were emotionally strong, independent, employed, self-sufficient and communicative and nurturant. The authors suggested that since lesbians typically had rejected both the stereotypical female gender role of dependence in relationships and the male role of independence without nurturance, that perhaps it was the apparently conflicting traits of autonomy and nurturance that contributed to the large number of breakups among the couples. The authors indicated that they did not believe that the lesbian goals of intimacy and independence were necessarily antithetical, but pointed out that this integration lacks historical role models.

In a follow-up to their initial research, Blumstein and Schwartz found that among the lesbian couples who had broken up, power-imbalance had been a significant factor. They also found that the person most likely to leave the relationship was the more powerful, forceful, aggressive person and the one who did less of the household work.

In their research, Caldwell and Peplau (1984) attempted to assess what lesbians wanted in terms of power in a relationship relative to what they were currently experiencing. In relationships with unequal power, the authors attempted to determine what factors contributed to the inequity. The authors assessed respondents' understanding of power in relationships by asking "who do you think should have more of a say about what you and your partner do together- your partner or you?" To assess what respondents thought about the balance of power in their own relationships 
they asked "who do you think has more of a say about what you and your partner do together - your partner or you?" Other power-related questions had to do with who chose the amount of time the respondents spent with each other and the amount of time they spent with other people as a couple.

To assess relative dependency on the relationship the authors asked "who do think is more involved in your relationship - your partner or you?" and "who do you think is more committed - your partner or you?" The authors also attempted to determine the strength of the respondent's feminist commitment and involvement as they believed that women with a feminist perspective might be more likely to achieve a balance of power.

In their findings, the authors reported that ninety-seven percent of the participants believed that each partner should have equal say in decisions regarding the relationship. But only sixty-one percent of the respondents said they actually had such a balance of power in their current relationship. The other questions regarding power yielded similar differences between ideal and actual. As the authors predicted, when one partner had a lower investment in the relationship, and the relationship had unequal power, it was the partner with lower investment who held the greater power. Also as they predicted, women with lower incomes and/or lower education often had less power in the relationship. They did not find any association between lesbian involvement in feminism and power in the relationship. They predicted that women in relationships with a power imbalance would be less satisfied with their relationships than those with equal power. Their data confirmed this. Women in unequal relationships were less satisfied with their relationship and expected to encounter more problems in the relationship in the future. Women in unequal relationships were substantially more worried about issues of independence/dependence and sexual 
exclusivity than were women in equal relationships.

Caldwell and Peplau found that women in relationships of equal power also scored higher on measures of respect, affection and "liking" for their partner, but found that power imbalance was unrelated to measures of attachment and intimacy. Women in unequal relationships were also less certain that their relationship would last through the next year. Since balance of power in lesbian relationships was correlated with satisfaction, it would be reasonable to assume that power imbalance would affect the longevity of the relationship. But the authors found no evidence to support that assumption.

In another article (Peplau, Padesky, and Hamilton 1982) the authors reported that lesbians in equal power relationships were much more satisfied with their relationship than were women in unequal situations. They did add however that it was unclear whether equal power created satisfaction in the relationship or rather that high satisfaction allowed for greater equality.

Falbo and Peplau (1980) found that women had a much stronger preference for equality in a relationship than either gay or straight men, and also that the women were much more likely to report having equal relationships. They found that women, significantly more than men, more highly valued both personal autonomy and intimacy and were more likely to attempt to combine the two priorities in their relationships.II another study, Peplau et $\underline{\text { al. }}$ (1978) predicted but failed to find associations between equality in the relationship and personal autonomy and attachment.

Blumstein and Schwartz(1983) found that the more powerful person in the relationship and/or the person more ambitious about her work was the person most likely to leave. Partners with unequal incomes were more likely to break up. Dependency of any kind in the lesbian relationships in this study was problematic, and 
inequality (e.g. finances, work, emotional investment) was the primary reason for the break-ups. The authors also found that partners who spent a longer than average time apart from each other were more likely to break up.

\section{Merger: Fusion and Enmeshment}

The second perspective on lesbian relationships focuses on issues of dependence within the relationship. Issues regarding the complicated interconnectedness and balance between intimacy and autonomy are pertinent to all couple types; but of particular interest to researchers of lesbian dynamics has been the tendency for lesbians to experience difficulty in maintaining personal boundaries within the relationship. While early researchers tended to judge lesbian problems of merger rather critically, somewhat as an indictment of the dysfunction of homosexuality, more current researchers have interpreted the phenomenon as a particular characteristic of a relationship between two women, just as there are specific characteristics of other relationship types, which are possibly, but not necessarily dysfunctional. Although merger between lesbians is impacted by homophobia, it appears to occur primarily as a consequence of sex-role socialization, and is a phenomenon with relational benefits as well as costs that speaks more about what it is to be female in this culture than what it is to be homosexual.

Krestan and Bepko (1980) used a definition borrowed from earlier work done by Karpel (1976) which defined fusion as:" a person's state of embeddedness in, of undifferentiation within, the relational context" (p 67). Krestan and Bepko argue specifically that women in merged relationships over-identify with each other and have difficulty maintaining personal autonomy within the relationship. The couple desires continual emotional closeness and has difficulty allowing for differences in beliefs, ideals or friendships. Decisions over spending time together or apart become 
prominent, and differences are seen as threatening. As most lesbians have been found to highly value personal autonomy and independence (Blumstein and Schwartz, 1983; Falbo and Peplau 1980) fusion creates unexpected and often unrecognized relationship problems that may manifest as affairs, sexual withdrawal, anger or emotional distancing.

Couples experiencing merger may repress all conflict or differences of opinion or may polarize and experience near constant conflict. Sexual activity often stops or decreases markedly in an attempt to create boundaries between intense intimacy and a perceived loss of self. Lesbian relationships experiencing serious merger problems often break up after two to three years (Krestan and Bepko 1980; Krieger 1983; Linderbaum 1981; Tripp 1975).

Researchers and clinicians have noted that while most lesbians in relationships experiencing difficulty need more personal distance, many are unable to achieve the autonomy they need, and do not even recognize that lack of autonomy is a problem. Elise (1986) points out that lesbian merger problems seem to be a paradox because the willingness to be gay in heterosexual culture would seem to indicate a high degree of autonomy, as the women gave up the possibility of traditional financial and emotional security for personal freedom in sexual orientation. And in fact, lesbians have been found to value autonomy within relationships more than heterosexual women and to score higher on measures of masculine or androgynous independence traits (Heilbrun and Thompson 1977; Kurdek and Schmitt 1986). Abbott and Love's (1972) early work on lesbianism suggested to Peplau that "lesbians, .... are not afraid to develop the qualities of independence, self-actualization, strength, and intelligence; and that in choosing a same-sex partner, lesbians choose personal autonomy over culturally prescribed female roles" (Peplau et al. 1978, p 9). Still, while many lesbians are able 
to maintain this autonomy and "instrumentality" (Dahlstrom 1989) out in the world, there is often difficulty resolving independence with relationship centeredness at home.

Most researchers (Elise 1986; Krestan and Bepko 1980; Smalley 1987) attribute this behavioral pattern to the sex role socialization of women. They note that women are raised to be dependent, to value relationships, and to focus on the needs of others before self. Many theorists (e.g., Chodorow 1980; Dinnerstein 1977; Gilligan 1982) have argued that the different individuation processes of boys and girls in early childhood has led girls to learn enhanced relational skills while boys have learned a stronger sense of self. Female emphasis on relationship has allowed women greater access to intimacy but also has created permeable personal boundaries that make selfdefinition more difficult.

Some clinicians point out that merger occurs in most couples, particularly in moments of intense intimacy, is not necessarily a dysfunctional phenomenon, and may even be a strength in lesbian relationships. Two women in a relationship together may have the potential for a much greater capacity for intimacy because of those relational skills and because of the more permeable personal boundaries (Burch 1982; Burch 1986; Chodorow 1987; Rubin 1983). The problem for lesbians appears to be the difficulty in balancing their need for personal boundaries with intimacy demands. ${ }^{1}$ In one study, Peplau et. al (1987) found that fifty percent of the lesbians reported problems with dependence/independence.

\footnotetext{
${ }^{1}$ Gay men experience few problems with fusion (Levine 1979; Peplau 1981;Peplau and Cochran 1981). They, like heterosexual men, tend to have stronger personal boundaries than women, and are unlikely to have problems with merger. Gay male couples do however often experience difficulties with relational skills and intimacy. Heterosexual couples tend to provide balance for each other with women more adept at providing the relational skills and men at creating personal space. Heterosexual women, however, often feel that their needs for intimacy and emotional closeness are not being met (Blumstein and Schwartz 1983).
} 
Peplau and colleagues examined lesbian relationship values as they applied to both dyadic attachment ("an emphasis on establishing emotionally close and relatively secure love relationships") and personal autonomy ("an emphasis on independence and self-actualization") in an attempt to understand how these relationship values were related to problems with independence/dependence, as well as to sexual exclusivity and future commitment.

The participants involved in the study rated on a scale from one to nine, twenty statements as they applied to their romantic/sexual relationship; ten items reflected beliefs about attachment and the other ten items reflected beliefs about autonomy. The authors found that most women in their sample strongly endorsed both values. This supported their belief that a value on attachment did not necessarily exclude a concurrent value on autonomy.

The authors found no relationship between attachment and the women's income, age, education or employment. They did, however, find that women who scored high on autonomy were significantly younger, were better educated, spent less time with their partners, were more likely to have an open sexual relationship, worried more about having an overly dependent partner, and were more likely to de-emphasize the need for future commitment. Women scoring high on attachment spent more time with their partner, were more certain of future commitment, were more likely to make major life changes (e.g. move to a different city) if necessary to insure that the relationship continue, had higher levels of closeness and satisfaction, and were less worried that personal independence issues would cause relationship problems. Their conclusion was that an emphasis on attachment is a culturally prescribed trait for most women, but that autonomy might reflect current changes in sex-role socialization of women (specifically as a result of the contemporary women's movement). 
Dahlstrom (1989) investigated merger within lesbian relationships by examining positive and negative feminine (renamed "communion") and masculine (renamed "agency") traits. She found that merger within lesbian relationships was related to low levels of the positive $(\mathrm{M}+)$ agentic trait (examples are self-assertion, self-protection, self-aggrandizement). Merger was not attributable to positive feminine traits such as relationship-centeredness but rather to a lack of sufficient agency traits to provide a balance. Androgynous subjects, those who scored high on both communion and agency scales, were shown to have the highest relationship quality and the most consistent interpersonal perception, regardless of sexual orientation (Kurdek and Schmitt 1986; Spence et al. 1978). As autonomy would be a M+ trait, I decided to examine in my research whether the lesbians in the current study who scored high on autonomy would also score low in fusion.

Peplau, Padesky and Hamilton (1982) found that the most common reason participants in their study cited for the break-up of their relationship was problems with independence within the relationship. Nearly seventy-five percent of the respondents listed this as a major factor in their break-up.

Falbo and Peplau, in their study of power strategies among both heterosexual and homosexual men and women, found that most differences were related to gender rather than to sexual orientation. Specifically, they found that women placed a greater emphasis than men on autonomy and on the need to combine their intimate relationship with friends and activities outside of the relationship, and were more likely to report egalitarian relationships.

Blumstein and Schwartz found that the lesbians in their study had the highest break-up rate of any of the four types of couples. This surprised them because they had found that being relationship-centered was critical to maintaining a successful 
relationship, and they found that most women are relationship centered. ${ }^{2}$ In examining their findings the authors concluded that there are two primary factors that lead to the high break-up rate in lesbian relationships. The first appears to be the complexity of successfully achieving a balance between high emotional intensity and priority in their relationships and an ambitious focus outside of the relationship. The second factor is the strong insistence on a balance of power and the difficulty of requiring a strong relationship focus from both partners while trying to carefully avoid any imbalance in levels of investment in the relationship.

Blumstein and Schwartz surveyed couples one year after the original study to find out who was still together and who had broken up. The authors found that the lesbians in their study held to the ideal of a relationship of two strong, independent women coming together in equality. They found that to the extent to which the relationship did not meet those expectations (i.e. one partner began to view the other as dependent) the more likely the break up. Women who saw themselves and their partners as strong and independent were much less likely to break up.

Blumstein and Schwartz concluded that lesbian relationships are the most obvious example of women adjusting to changes in women's roles and expectations. While lesbians still hold on to stereotypical expectations for women, such as primacy of relationships and equality, these women are now adding the new values of personal autonomy and independence. The authors felt that these attempts to create new female roles in relationships were a challenge many of these lesbians had not yet been able

\footnotetext{
${ }^{2}$ Kurdek and Schmitt (1986) found that among all types of couples, heterosexual and homosexual, those with one or both partners with androgynous or feminine sexrole characteristics had the highest relationship quality. They believed that this was attributable to the relationship-enhancing characteristics of androgynous or feminine sex-role traits of relationship-centeredness (as opposed to the masculine and undifferentiated characteristics of being task-minded, low in nurturance, dominant).
} 
to manage successfully.

\section{Feminism}

The third perspective suggests that feminism might have an effect on the makeup and duration of lesbian relationships. Peplau et al. (1978) studied attachment and autonomy in lesbian relationships. The authors hypothesized that lesbian feminists would put a high value on independence and autonomy and a lower value on monogamy and permanence within the relationship. They felt that since feminism stressed personal independence and self-actualization, lesbians (to the extent that they are feminists) might be caught trying to reconcile two seemingly conflicting relationship values: the one for interdependence, attachment and relationship centeredness and the other emphasizing feminist values of autonomy, independence, and sexual freedom. The authors were primarily interested in what effect feminism had on lesbians' attitudes toward love relationships and the effect that these attitudes had on their relationship satisfaction, commitment and problems.

Peplau and colleagues had respondents rate on a scale of one to nine, twenty statements regarding romantic/sexual relationships. These broke down into two scales, one on personal autonomy ("an emphasis on independence and self-actualization that may lead to a questioning of traditional patterns of love relationships") and one on dyadic attachment ("an emphasis on establishing emotionally close and relatively secure love relationships)". They found, as they expected, that feminism was definitely linked to greater emphasis on independence and autonomy. The women who scored high on one scale scored lower on the other, but only slightly. This concurred with their expectation that an emphasis on attachment was not incompatible with an emphasis on autonomy. 
The authors also found that personal autonomy was most highly valued by those lesbians most active in feminism. Those scoring high on autonomy were less religious, younger and had more education than those who scored lower. In their sample, relationship longevity was found to be negatively related to autonomy. Those women who scored higher on autonomy had been in their relationship a shorter time than those scoring lower. The authors were not certain whether this was due to a lower value given to relationship permanence by those scoring high on autonomy or simply to the younger age of this group of women. Women who scored high on autonomy were much less likely to live with their partners and less likely to see their partner daily. These same women, however, seemed as satisfied with their relationship as the women who scored low on autonomy and lived with or saw their partner more frequently.

Peplau, Cochran, Rook and Padesky (1987) also hypothesized that lesbians who scored low on autonomy would be primarily monogamous. In their sample they found that less than a third of the women had had sex with someone other than their partner since their relationship began. Those who scored high in personal autonomy were more likely than those who scored low to have had sex outside of their relationship.

In an earlier study, Peplau, Padesky and Hamilton (1982) found no association between relationship satisfaction and feminist attitudes. Relatedly, Caldwell and Peplau (1984) found no association between the balance of power in the relationship and participation in feminist activities, although they mentioned that this might be because a majority of the women in their sample had "pro-feminist beliefs".

Blumstein and Schwartz (1983) commented that while feminism did create a favorable climate for the idea of non-monogamy, and many lesbians did support that ideology, most had a difficult time actually practicing it. They emphasized that 
lesbians live between two contradictory sets of values- one that denounces monogamy as a creation of patriarchy and reflective of ownership, and another which reflects more traditional female values particularly concerning relationship loyalty. They found that lesbians, like most women, "prefer sex to take place in a context of warmth, affection and respect, not to be a purely physical experience."

\section{Structural Support}

A fourth perspective, articulated best by Blumstein and Schwartz (1983) regards relationship duration as partially a product of structural supports. The theoretical premise is that heterosexual relationships last longer than homosexual ones because, in addition to other factors, heterosexual couples begin their marriage with joint acquisitions which create ties that keep them together through the rough times. The assumption is that co-ownership of homes, cars, furniture, etc. along with joint financial accounts, wills and stock and bonds, will create a web of interconnectedness that will assist couples in staying together. Blumstein and Schwartz noted that keeping separate finances does reduce conflict for all types of couples, but hypothesized that it also facilitates ease of relationship dissolution should difficulties arise. ${ }^{3}$

\section{$\underline{\text { Sexuality }}$}

An additional issue in the literature is lesbian sexuality. There are many conflicting research findings and many differing interpretations regarding such sexuality. Blumstein and Schwartz (1983) got comprehensive information on lesbian sexuality within relationships from over 1500 lesbians. The authors found, in

${ }^{3}$ The authors came to this hypothesis after examining the results of their research with six-thousand couples. They did not test this hypothesis. 
accordance with most other studies, that lesbians have sex less often than other types of couples. In this study, lesbians were more likely than any other group to wish they had more sex (eighty-three percent of the lesbians expressed a desire to have more sex in their relationship ${ }^{4}$ ).

Tripp (1975) concluded that lesbian sex often stopped after approximately three years in a lesbian relationship and suggested that it was due to the "relatively low libido of many women" (p154). Lindeman (1988) described the apparent lack of high lesbian sexuality as a consequence of merger and "a way of compensating for the loss of self which creates some of the needed separateness." But other researchers (Blumstein and Schwartz 1983; Loulan 1987) found that most lesbians are having regular sex in their relationships.

Researchers agree that for lesbians non-genital physical contact is much more highly valued than for other couples. Lesbians regarded hugging, cuddling and touching as very crucial and an end in themselves not just a precursor to genital sex. They (Blumstein and Schwartz 1983; Loulan 1987) found lesbians highly satisfied with the quality of their sex lives despite low frequency, although those lesbians with higher levels of sexual frequency were more satisfied with their relationship in general than those with lower levels.

The authors found that their respondents had mixed feelings on the subject of monogamy. While many supported the idea of non-monogamy (or of the option of having sexual choices), most did not practice it. The authors noted that casual sex is not a significant piece of women's acculturation in this society, as it is for men. While their study indicated that both straight and gay men were able to be non-

${ }^{4} 80 \%$ of heterosexual men, $70 \%$ of heterosexual women, and $56 \%$ of gay men also wished they had more sex in their relationship. 
monogamous while still being very satisfied with their current relationship and its sexuality, lesbians were most likely to be non-monogamous when their relationship was in trouble. Further, lesbian non-monogamy was usually a romantic, rather than casual, sexual encounter and therefore more likely to disrupt the stability of the primary relationship. Many of the lesbians whom Blumstein and Schwartz interviewed directly said that they or their friends had experienced the intense complications that arose out of instances of non-monogamy and for that reason chose to be monogamous, even though they intellectually still supported the concept of non-monogamy.

Of the 1500 lesbians surveyed by Blumstein and Schwartz, seventy-one percent said that it was important to them to be monogamous. Twenty-eight percent said there had been one or more instances of non-monogamy since the beginning of their relationship. Thirty-eight percent of the lesbians who had been together two-to-ten years, and forty-three percent of those who had been together more than ten years had been non-monogamous during their relationship. The authors noted that within these lesbian relationships, non-monogamy is often something that only happens once, as the complications mentioned earlier deter any further episodes. 


\section{CHAPTER III}

\section{METHODOLOGY}

Participants in this study were recruited by announcing and calling for volunteers at local and national lesbian church functions, by posting a notice at Portland State University and at several women's bars in Portland, and by contacting lesbians in Portland who contacted friends and family across the United States whom they believed might be interested in participating in the study.

Participants were limited to those lesbian couples who had been in a relationship for five or more years. In trying to understand the nature of lesbian longterm relationships, and the possible differences between lesbians in long-term and short-term relationships, I had to decide what "long-term" meant. I wanted couples who were in their relationships with deliberate intention and commitment. It was these qualities that I felt might be associated with lesbian relational dynamics that differed from those in earlier research where many of the couples had been together only briefly. While relational longevity does not de facto represent intention and commitment, it seemed to me to be preferable to use this behavioral indicator than to rely on an as-yet-unproven statement of intent. Five years, while obviously an arbitrary dividing line, seemed long enough to weed out couples who were only together casually, and short enough to find respondents.

Both members of the couple participated. Each of the women was asked to fill out the survey separately, without consulting her partner. They then were asked to put 
both surveys in a return envelope to me before discussing the survey with each other. I had no way of insuring that the partners did not consult with each other while filling out the questionnaire. I did, however, notice that in the section where they were asked which items they had purchased together and in what year of their relationship, many of the couples' answers differed slightly from one another, perhaps an indicator that they had filled out the questionnaire separately.

Questionnaires were given or mailed directly to potential participants who requested them, or were given to third parties who then sent or delivered them to the participants. The cover sheet guaranteed anonymity and explained how they could anonymously receive questionnaires for friends who might wish to participate in the study. The questionnaire itself was ten pages and contained ninety-six questions. The majority of the questions were adapted from prior studies of lesbians relationships. Demographic data on the participants were also collected.

Due to societal pressures and prejudices, women who are lesbians often identify themselves as such only to small groups of intimate others. This makes sampling the lesbian population difficult. Random samples are not possible. Subjects available for this study may represent lesbians who are more comfortable with their lesbian identity and more likely to socialize with other groups of lesbians. This was a snowball sample with all the limitations of not having a random sample. Clearly missing in the current sample are lesbians of color, of lower education, of lower income and of those living in isolated rural areas. This sample is skewed in that the women were primarily white, middle class, well educated lesbians, from primarily large cities and their surrounding neighborhoods. While this is not a representative sample of lesbians, it is demographically similar to samples used in the prior research around which this study was designed. 
This questionnaire, and questionnaires in general, have a limitation of examining more about what a person believes about their experiences than about their actual reality. It is quite possible, particularly in the section on power and equality, that I was more likely to have uncovered what people believed was true about the power balance in their relationship than what was true.

Most of the questions used in this questionnaire were adapted from previous studies in order to make comparisons with those findings. However, due to the necessary modifications in some of the questions or in the structure of the answers, comparisons made here are less than exact.

A prejudice inadvertently built into the questionnaire was an assumption that lesbians in a long-term relationship would be living together. Apparently, all of the sixty-two couples did live together, or at least answered the questionnaire as if they did. In retrospect, however, I realized that not all lesbians in long term relationships live together and that should have been reflected in the questionnaire. (See the appendix for a copy of the questionnaire.)

\section{Power, Equality, Attachment and Autonomy}

Issues regarding power and equality were of major importance in many of the early studies and were also addressed in this study. Regarding the distribution of power and equality, respondents were asked whether they or their partner had the most education, money, influence over how much time spent was spent with the partner, and say about important decisions. There were also questions asking who was more committed, who had altered their habits and ways of doing things more to please the other, and who did the most housework. On a seven point scale the responses ranged from "I much more" to "she much more". 
The questions on dyadic attachment asked about the importance of: sharing as many activities as possible, living together, spending as much time together as possible, sexual fidelity, knowing the relationship will endure, sexual compatibility, and knowing my partner depends on me.

Questions on the autonomy scale ranked the importance of having: similar attitudes about women's issues, similar political views, a supportive group of friends, an equal power relationship, and major interests outside the relationship. Respondents were asked to rate each item on a seven-point scale, ranging from "most important" to "least important." This scale was modified from the scale used in the Peplau and colleagues earlier research. The original instrument included three additional questions, asking about the importance of non-monogamy, of practicing new sexual techniques, and of enjoying the relationship now without insisting on a future commitment. These questions do not, in my view, serve well as indicators of autonomy, and so I did not use them. There were several specific reasons that I excluded these questions. A person might choose to be monogamous for reasons that would not be related to personal independence issues. Relatedly, the question on the importance of practicing new sexual techniques seems to relate more to an individual's desire for new experiences in general. The importance of trying new sexual techniques with one's partner may be more relevant within the first few years of a relationship than it is after ten years. As to the question regarding the importance of enjoying the relationship now without insisting on a future commitment, it seemed to me that after being in a relationship five to ten years, the expectation and desire for the relationship to continue would no longer be related to autonomy.

Questions on dyadic attachment and personal autonomy were adapted from earlier work by Peplau and colleagues (1978) and had answers that ranged from "most 
important" to "least important" on a seven point scale. The individuals' responses to these questions were combined into two scales, one attachment and the other autonomy, which were examined in relation to each other as well as to feminism.

In examining the dynamics of power and equality, early researchers also looked at the level of relationship commitment a person had. The present study included seven questions adapted from Caldwell and Peplau(1984) and Peplau et al.(1978) regarding the level of commitment. These questions included the willingness to buy a home together (which many of them had done), to financially support the partner if necessary, to relocate if necessary, and the level of certainty that the relationship would last five more years.

Two questions in the commitment section were seen as problematic in that they lacked a "depends" choice. The answers to the questions would you be willing to "buy a home with your partner" or "financially support your partner if necessary", were limited to "yes" and "no" in order to force respondents into the choice most likely. However, several people wrote on the questionnaire that their choice would depend on many situational factors and could not be simply answered "yes" or "no". Some of these were coded as "no response", while several others gave a "yes" or "no" answer(and these were coded as such) while explaining it would be conditional. Several others wrote that they would be unable to relocate regardless of how much they might want to due to family or economic responsibilities.

\section{Fusion and Enmeshment}

In order to examine the phenomenon of fusion four statements from Blumstein and Schwartz (1983) were used:

There are times when I am with my friends and I do not want my partner along. 
It is important to me that my partner spend some time without me.

It is important to me that my partner and I spend all of our free time together.

It is important to me that my partner and I each have some interests, activities, and friends that we pursue without the other.

For these statements the answers ranged from "strongly agree" to "strongly disagree" on a seven point scale. The responses to these statements were later averaged to create a fusion scale.

When I created the fusion scale, fifty percent scored below the midpoint (four), and fifty percent scored above the midpoint(four). This is the scale that I first used in tabulating results. However, because of the nature of the questions asked, I felt that the midpoint(four), or even slightly above the midpoint (four and a half) was still an indication of fusion even though it fell into the category of "less fused". Therefore I redid the division on the fusion scale, creating new categories of "less fused", (five or above), and "more fused" (four and a half or below)

\section{$\underline{\text { Feminism }}$}

In order to address the issues raised about the impact of feminism on lesbian relationship, four questions were asked:

Do you consider yourself to be a feminist?

How important is feminism to you?

How involved are you in feminist activities?

How much do you read feminist materials?

The range of possible answers was from "very", to "not at all" on a seven point scale. The original idea was to create a feminism scale. However, women who scored high on the first two questions were not necessarily interested in feminist activities or readings. As I was primarily interested in salience, not activity, I ran my cross- 
tabulations using the single question "how important is feminism to you?" to indicate the level of feminism.

\section{$\underline{\text { Structural Support }}$}

Blumstein and Schwartz theorized that most married couples begin their relationships with joint financial ties and increase those ties throughout their relationship, thus making dissolution more difficult, and, that if gay and lesbian couples were to do the same, their relationships might have greater longevity.

To examine this theory I asked fourteen questions regarding financial arrangements and legal documents, again taken from the Blumstein and Schwartz study. These questions addressed financial pooling of resources, joint checking and savings accounts, wills, power of attorney, commitment ceremonies, and in what year of their relationship they did these things. I also asked one question about the type of item purchased jointly by the couple, and in what year of their relationship. Respondents were asked if they had bought a house, car, appliances, furniture or other major purchases, and if so during what year in their relationship had they done so. In particular I was looking to see if the "structural ties" were made early in the relationship where they may have lent support to the longevity possibilities of the relationship, or if the ties came gradually over time as a result of a continuing relationship.

\section{$\underline{\text { Sexuality }}$}

The current study included nine questions regarding sexuality, adapted from Blumstein and Schwartz (1983). There were questions on the number of past sexual relations, sexual satisfaction in the relationship, frequency of sexual activity, whether 
they would like sex more or less often, how often they experience orgasm during sex, number of prior relationships, and whether they would leave the relationship if sexual activity ended.

There were three questions regarding monogamy. The first two questions were adapted from Blumstein and Schwartz and asked if the respondent had been nonmonogamous in her relationship and what her understanding of the couple's agreements regarding monogamy were. The last question, original to the current study, asked for the respondents' individual belief about monogamy.

\section{$\underline{\text { Other }}$}

Ten questions adapted from Blumstein and Schwartz (1983), assessing comfort with lesbianism and level of "outness", were asked. Questions were asked about levels of "outness" with different family members, their degree of acceptance, "outness" with friends, co-workers and doctor, and whether or not differences in levels of "outness" have caused any conflicts within the relationship. "Outness", measured separately by several of the above mentioned questions, was then cross-tabulated with fusion, frequency of sex, and age.

In examining the data it became clear that several questions were problematic. For example, the questions on respondents' religiosity were too limiting. The use of the word "spiritual" rather than "religious" may have been preferable. Several people wrote on their questionnaire that they were not at all religious but considered themselves to be very spiritual. I coded these responses as very religious. As lesbians have often been denounced by many major religious organizations, the word "religious" may have more negative connotations to lesbians than to the general public. The question on attendance at worship encountered the same problems. Several 
people wrote in the margins that worship for them was a daily part of their lives as spiritual people and not a place they went to.

The data were analyzed using tabular and correlational methods. No tests of significance were performed because the sample was not random. 


\section{CHAPTER IV}

\section{FINDINGS}

\section{The sample}

The demographic data revealed that the majority of respondents were between the ages of thirty and fifty, white, college educated and middle class. Specifically, forty-two percent of the respondents had either a Masters degree or Ph.d, and another ten percent had done some graduate work; two-thirds described their occupation as either professional/technical or manager/administrator. Almost all of the respondents described themselves as more politically liberal than conservative with sixty percent labeling themselves as extremely liberal. This is clearly not a representative group of lesbians, but was similar in make-up to the lesbians studied in the research previously described.

One difference in the characteristics of the women in this study compared to those in other similar studies is their religious nature. Over half of the respondents described themselves as "somewhat" to "very" religious and almost a third went to worship between one and four times a month. The likely reason for this unusual pattern is that announcements regarding this survey were made at large lesbian Methodist gatherings that were occurring at the time I was collecting my data. I am unclear as to what impact this might have on the findings. One could speculate that it might indicate a more sexually conservative group; however some research (Blumstein and Schwartz 1983) has indicated that a person's "religiosity" does not affect her or his sexual activity. 
Sixty-seven percent of the participants had been together between five and eight years, twenty-three percent between nine and eighteen, and ten percent had been together over eighteen years. Approximately half of the lesbian couples surveyed lived in Oregon with half of that number living near Portland. The rest of the couples came from areas across the United States. Selected demographic findings are listed in Table 1.

Table 1

\section{BACKGROUND CHARACTERISTICS OF RESPONDENTS BY PERCENT $(\mathrm{N}=105)$}

Age between thirty-one and forty Age between forty-one and fifty 46.0 Have a Bachelors degree 31.0 Have a Masters degree 23.8

Professional/Technical occupation 37.1

Manager/Administration occupation 48.6 Student as occupation 14.3 Individual income below $\$ 25,000$ 12.4 64.8 Attend worship once a week Attend worship 1-3 per month "Very" or "quite" religious Politically "extremely" or "quite" liberal 60.0

Research on heterosexual couples as well as lesbian couples has indicated that partner similarity is very important in relationships (Cotton 1975; Peplau and Cochran 1987; Peplau, Pedasky and Hamilton 1982). The current study very closely matched the findings of earlier work, with almost two-thirds of the respondents similar in education, age, career and income. Differences in age, education and income were not related to relationship satisfaction in either previous (Kurdek and Schmidt 1986; Peplau et al. 1982; Peplau et al. 1986) or the current study. ${ }^{1}$

\footnotetext{
${ }^{1}$ Satisfaction was measured by different criteria in these studies.
} 


\section{Power and Equality}

Previous researchers have found that lesbians feel strongly about having equal power with their partner. Despite that ideal, however, a sizable minority of the lesbians studied reported some inequality. The research reported that lesbians have considerable difficulty with inequality and it was reported in one study as a significant factor in relationship dissolution (Blumstein and Schwartz 1983). As the couples in my sample had already been together five or more years, I wondered if their issues regarding power and equality would look different. It could be argued that women in longer term relationships might have resolved their power imbalances through time, or that women who had a more balanced relationship initially would stay together longer.

To determine the respondents' beliefs about power in a relationship I asked the question, used by earlier researchers (Peplau et al. 1976; Peplau 1979), "who do you think should have the final say about important decisions affecting you and your partner?" The current sample responded exactly as those in the prior research had done (Caldwell and Peplau 1984; Peplau et al. 1978), with ninety-eight percent indicating that partners should have equal power. However, in the question designed to indicate who actually had more power, the two samples differed.

When I asked "who has more say about important decisions affecting you and your partner" eighty-six percent said they had exactly equal influence, compared to only sixty-one percent in an earlier study. ${ }^{2}$ Answers to two other balance of power questions, i.e., "which partner has the greater influence in deciding how much time the partners will spend" 1) "with each other" or 2) "with others", replicated the findings

\footnotetext{
${ }^{2}$ In Peplau and Cochrans (1980) study 59\% of lesbians, $45 \%$ of heterosexual women, $40 \%$ of heterosexual men, and $38 \%$ of gay men said their relationship was equal.
} 
of the earlier research, with two-thirds reporting equal power, and most of the others reporting slightly less than equal power (see Table 2). In the other questions on equality, again similar to previous findings, approximately two thirds of this sample reported an equal balance in their relationship. ${ }^{3}$

Table 2

BALANCE OF POWER ON SELECTED TOPICS, BY PERCENT $(\mathrm{N}=104)$

\begin{tabular}{||l||l|l|l||}
\hline & $\begin{array}{l}\text { Partner } \\
\text { more }\end{array}$ & $\begin{array}{l}\text { Exactly } \\
\text { Equal }\end{array}$ & I more \\
\hline Influence over imp. decisions & $2.9 \%$ & $85.7 \%$ & $10.5 \%$ \\
\hline Influence over time together & $23.9 \%$ & $65.7 \%$ & $9.6 \%$ \\
\hline Influence over time w/others & 22.8 & $59.0 \%$ & $18.2 \%$ \\
\hline Who has altered behavior & $17.2 \%$ & $61.9 \%$ & $18.0 \%$ \\
\hline Who is more committed & $9.6 \%$ & $88.6 \%$ & $2.9 \%$ \\
\hline
\end{tabular}

Interestingly, a third of the respondents also described a substantial betweenpartner difference in education and/or in income. However, differences in partners' education or income were not related to the distribution of power in the relationship. This echos findings by some of the earlier researchers that lesbians seem to avoid financial imbalance within their partnerships whenever possible.

In the current study, most of the respondents who did not answer "exactly equal" on balance of power questions, answered "almost exactly equal". The lesbians in this particular sample consistently seemed to feel quite equal in their relationships. Peplau, Padasky, and Hamilton (1982) found that those relationships with a

${ }^{3}$ On these questions most of the responses fell just to either side of "exactly equal" with $85 \%-95 \%$ indicating "mostly equal". The categories were collapsed so that only those answers of "both equal" were deemed "equal". 
greater balance of power were between partners who were more satisfied with their relationship, more likely to see their relationship continuing into the future, and more committed to the relationship. In order to examine levels of commitment the respondents in both the prior study and the current study were asked if they would be willing to move if their partner needed to relocate for an attractive job offer or schooling opportunity. ${ }^{4}$ Eighty-eight percent of those in the current study said they would definitely or probably move if their partner needed them to. They were also asked how certain they were that they would still be together in five years. In the previous work only twenty-six percent felt certain that their relationships would last five years. In contrast, the great majority of the current sample was certain(76\%) or pretty sure $(12 \%)$ that they would still be together in five years.

Other questions about commitment yielded similar results. When asked if they would financially support their partner if necessary, one hundred percent said yes. When asked if they would buy a home with their partner, ninety-five percent said they would or already had. When asked the question "who do you think is more committed...." eighty-eight percent of the current study said they were exactly equally committed to the relationship with the other twelve percent responding that they were almost equally committed. This was quite a bit higher than in the original study (Caldwell and Peplau 1984) where only sixty-one percent of the respondents reported equal commitment.

A much higher percentage of respondents in the current sample than in the earlier sample reported equal relationships, high level of commitment and apparent

\footnotetext{
${ }^{4}$ Two other studies of lesbian populations asked this question. In one study (Peplau et al. 1978) less than fifty percent said they would definitely or probably move with their lover. The median length of the relationships in this study was 2.5 years. In a second study (Gordon 1980), eighty percent said that they would move. The median length of the relationships in that study was 4.2 years.
} 
satisfaction. These attitudes may very well be related to the long-term nature of the relationship. Additionally, however, they might also reflect dimensions of the psychological make-up of the participants. Respondents were asked questions to reflect their relationship centeredness or "dyadic attachment". In the current study those who had higher levels of dyadic attachment had been in their relationships slightly longer than those with lower levels (see Table 3 ).

The current sample answered questions on both dyadic attachment and personal autonomy. Similar to respondents in previous research, the respondents scored high on both scales, and those who were high on one scale usually were slightly lower on the other (see Table 4). Those who scored high on dyadic attachment were most likely to feel certain that they would relocate with their partner if necessary. Those who scored lower on the dyadic scale were likely to respond that they probably, rather than certainly, would move. Likewise, those who scored lower on autonomy were also more likely to be certain they would move, while those who scored high on autonomy thought they would probably move (see Tables $5 \& 6$ ).

Peplau et al. (1978) found that those who scored high on the dyadic attachment scale were much more likely to say that they would be willing to relocate with their partner. Those who scored high on the autonomy scale were less likely to say they would move with their partner and less likely to expect their relationship to continue into the future.

Table 3

MEAN NUMBER OF YEARS TOGETHER BY LEVEL OF DYADIC ATTACHMENT $(\mathrm{N}=105)$

\begin{tabular}{|l|c|}
\hline \hline Mean \# of years together/TOTAL & 9.46 \\
\hline Mean \# years together/lower attachment & 8.19 \\
\hline Mean \# years together/higher attachment & 10.71 \\
\hline
\end{tabular}


Table 4

\section{DYADIC ATTACHMENT MEAN BY LEVEL OF AUTONOMY \\ $(\mathrm{N}=105)$}

\begin{tabular}{|l|l|}
\hline \hline Attachment mean/ total population & 5.57 \\
\hline \hline Attachment mean/ lower in autonomy & 5.74 \\
\hline \hline Attachment mean/ higher in autonomy & 5.25 \\
\hline
\end{tabular}

Table 5

WILLINGNESS TO RELOCATE FOR PARTNER BY LEVEL OF AUTONOMY, BY PERCENT

$(\mathrm{N}=105)$

\begin{tabular}{||l|l|l||}
\hline \hline & $\begin{array}{l}\text { Lower } \\
\text { Autonomy } \\
(\mathbf{N = 5 6 )}\end{array}$ & $\begin{array}{l}\text { Higher } \\
\text { Autonomy } \\
(\mathbf{N = 4 9 )}\end{array}$ \\
\hline Would relocate & $62.5 \%$ & $44.9 \%$ \\
\hline Probably relocate & $26.8 \%$ & $40.8 \%$ \\
\hline Wouldn't relocate & $7.1 \%$ & $8.2 \%$ \\
\hline & $100 \%$ & $100 \%$ \\
\hline
\end{tabular}

Table 6

DYADIC ATTACHMENT MEAN BY WILLINGNESS TO RELOCATE FOR PARTNER

$(\mathrm{N}=105)$

\begin{tabular}{||l|l||}
\hline Attachment mean/ total & 5.57 \\
\hline Attachment mean/ would definitely relocate & 5.84 \\
\hline Attachment mean/ would probably relocate & 5.38 \\
\hline Attachment mean/ who would not relocate & 4.60 \\
\hline
\end{tabular}


Merger: Fusion and Enmeshment

As described earlier, the merger "problem" seems to be a consequence of female sex-role socialization toward relationship centeredness without an equally strong sense of agency or self-focused action. Research has suggested that lesbians in enmeshed relationships often break up after two to three years, and/or that their sexual activity declines or stops (Krestan and Bepko 1980; Krieger 1983; Lindenbaum, 1981). When lesbians have been asked to list the primary reasons why past relationships had ended, "problems with independence/dependence" was one of the most frequently given answers in several different studies (Blumstein and Schwartz 1983; Gordon 1980; Peplau, Pedasky, Hamilton 1982).

The current sample has been together at least five years with the median length of the relationship seven years, and the mean nine and a half years. I expected to find that the women in these relationships were not experiencing problems with fusion. The fusion scale was created by averaging responses to four questions on fusion. Fifty percent of the sample scored at or below the midpoint (four)(more fused) and another fifty percent scored above the midpoint (less fused). The cross tabulation of the fusion scale with age, sexual satisfaction and frequency of sexual activity yielded no notable relationships. I then changed the fusion scale, using 4.5 and below to indicate "more fused" and above that, "less fused". 5 Seventy five percent of the respondents scored 4.5 or below on the scale, or "more fused". Using the second scale I found several relationships. Those scoring highest in fusion were likely to be over age forty and less feminist than those scoring lower in fusion (see Table 7).

\footnotetext{
${ }^{5}$ The reasons for this change in the scale were explained earlier in the methodology section.
} 
Table 7

\section{IMPORTANCE OF FEMINISM BY LEVEL OF FUSION, BY PERCENT $(\mathrm{N}=105)$}

\begin{tabular}{||l|l|l||}
\hline & $\begin{array}{l}\text { Higher in } \\
\text { Fusion } \\
(\mathbf{N = 7 8 )}\end{array}$ & $\begin{array}{l}\text { Lower } \text { in } \\
\text { Fusion } \\
(\mathbf{N = 2 5})\end{array}$ \\
\hline $\begin{array}{l}\text { Feminism of medium } \\
\text { or low importance }\end{array}$ & $29.4 \%$ & $3.7 \%$ \\
\hline Feminism important & 70.5 & $96 \%$ \\
\hline & $100 \%$ & $100 \%$ \\
\hline
\end{tabular}

Earlier research had indicated that fusion in lesbian relationships negatively affects relationship longevity and the couple's sexual relationship (Krestan and Bepko,1980; Krieger, 1983; Lindenbaum 1981). In the current study fusion was not associated with longevity, but was related to sexual frequency. Surprisingly, however, and contrary to earlier findings, those scoring higher on fusion had higher sexual frequency than those scoring lower on fusion (explained further in the sexuality section).

One of the factors often mentioned in studies or commentaries on enmeshment in lesbian relationships is the effect of societal homophobia (fear of and prejudice against homosexuals) on the relational dynamics of the couple as well as on the individual (Dahlstrom 1989; Elise 1986; Krestan and Bepko 1980). Elise notes that "societies failure to see the couple as a viable unit results in an intensification of the boundary between the couple and the outside world, and a subsequent decrease in the individual boundaries within the relationship (Elise 1986, p.306). She notes that problems with family pressures and with heterosexual social situations are several difficult aspects of coping with homophobia that can affect a relationship. A lesbian's 
ability to be "out" and to find support within her family or social situations might change the dynamics of fusion.

In the current study several questions were asked in an attempt to identify how "out" the respondents were and how supportive their immediate family was. I speculated that the more "out" a woman was, the less impact societal prejudices would have upon her. Likewise, if a lesbian's own immediate family was supportive of her relationship, then this too should deflect the impact of outside pressures. I expected that fusion would be negatively related to "outness" and acceptance by family.

Close to a third of the respondents were "somewhat" to "completely" out at school and work, and with their immediate and extended families. Not surprisingly, women over fifty were much less likely than those younger to be "out". More than two-thirds said they felt that their partner's mother made them feel like part of their family, and slightly less than two-thirds said the same for their partner's father (but in many of these cases the parents were supportive of the partner while unaware or not acknowledging the true nature of the relationship). Twenty percent of the sample was not out to anyone at work, school or family and the same percentage found their partner's parent(s) clearly did not want them "in the family". ${ }^{6}$

As was expected, those women who were high in fusion (second scale) were twice as likely as those low in fusion to be "out" to no members of their immediate family. Of those higher in fusion, half were out to all of their immediate family, as compared to seventy percent of those lower in fusion (see Table 8).

${ }^{6}$ This percentage is of those for whom the question was applicable. Twenty-two percent said the questions was not applicable regarding their partner's mother, and forty-six percent regarding their partner's father. Some respondents' partners did not have parents available or alive. 
Table 8

FUSION BY "OUTNESS" WITH IMMEDIATE FAMLY, BY PERCENT

$(\mathrm{N}=105)$

\begin{tabular}{||l|l|l|l|l||}
\hline & $\begin{array}{l}\text { out to no } \\
\text { immediate } \\
\text { family }\end{array}$ & $\begin{array}{l}\text { out to some } \\
\text { immediate } \\
\text { family }\end{array}$ & $\begin{array}{l}\text { out to all } \\
\text { immediate } \\
\text { family }\end{array}$ & \\
\hline High fusion $(\mathrm{N}=78)$ & $24 \%$ & $24 \%$ & $50 \%$ & $100 \%$ \\
\hline Low fusion $(\mathrm{N}=27)$ & $11 \%$ & $19 \%$ & $70 \%$ & $100 \%$ \\
\hline
\end{tabular}

Table 9

FUSION BY LEVELS OF "OUTNESS"

AT SCHOOL OR WORK

BY PERCENT

$(\mathrm{N}=105)$

\begin{tabular}{||l|l|l|l||}
\hline & $\begin{array}{l}\text { Somewhat or } \\
\text { completely "out" }\end{array}$ & $\begin{array}{l}\text { Not } \\
\text { "out" }\end{array}$ & \\
\hline High Fusion (N=78) & $59 \%$ & $40 \%$ & $100 \%$ \\
\hline Low in Fusion (N=27) & $75 \%$ & $23 \%$ & $100 \%$ \\
\hline
\end{tabular}

$\underline{\text { Feminism }}$

Respondents were asked if they considered themselves feminists and if feminism was important to them. The rating was from one ("not important") to seven ("very important"). Eighty-eight percent gave ratings at or above the midpoint(four), seventy-eight percent with a five or above, and sixty-three percent answered with a six or seven. It does not seem, then, that lesbians in longer-term relationships are less likely to be feminist as has been suggested.

Peplau et al. expected to find that feminist lesbians highly value personal autonomy and place a lower value on sexual exclusivity as well as and on the need for 
permanence in relationships. They found that the more feminist the women were the more likely they were to score high on autonomy. The higher they scored on autonomy, the more likely they were to have been non-monogamous (although only a third of their sample had ever been non-monogamous). In the current study feminism was also found to relate to autonomy (see Table 10). Ninety-four percent of the people who scored high on autonomy said feminism was very important to them, compared to sixty-one percent of those scoring low on autonomy. Feminism was also found to be related to dyadic attachment. Those that reported that feminism was more important in their lives had a slightly lower level of dyadic attachment.

Autonomy was related to monogamy, with those scoring high on autonomy twice as likely to have been non-monogamous. It is important to note, however, that only twenty-two percent of the respondents had ever been non-monogamous, and eighty-two percent of the sample believed that monogamy was essential for a healthy relationship. Ninety-seven percent of the current respondents said that it was "extremely" or "quite" important to them that their relationship be permanent even though the majority of the respondents also said feminism was very important to them.

Table 10

AUTONOMY BY IMPORTANCE OF FEMINISM, BY PERCENT

$(\mathrm{N}=105)$

\begin{tabular}{||l|l|l||}
\hline & $\begin{array}{l}\text { Lower in } \\
\text { Autonomy }\end{array}$ & $\begin{array}{l}\text { Higher in } \\
\text { Autonomy }\end{array}$ \\
\hline $\begin{array}{l}\text { Feminism of medium or } \\
\text { low importance }\end{array}$ & $37 \%$ & $6 \%$ \\
\hline Feminism important & $63 \%$ & $94 \%$ \\
\hline & $100 \%$ & $100 \%$ \\
\hline
\end{tabular}

In certain prior studies, emphasis on equality in lesbian relationships has been 
linked to general feminist beliefs (Barnhart 1975; Peplau et al. 1978). However, in other research that link has not been apparent (Caldwell and Peplau 1984). ${ }^{7}$ In the current study the more feminist the respondents were, the more they were likely to be in an equal relationship. And, those who scored low or moderate on feminism were more likely to score higher on dyadic attachment.

\section{Structural Supports}

Blumstein and Schwartz speculated that stability and longevity of gay and lesbian relationships might be facilitated by the creation of structural supports that resemble those that serve a similar function in the heterosexual community. Specifically they noted that " some of our gay couples, consciously or unconsciously, create financial arrangements that parallel those of married couples. They buy property together, make investments and become so financially intertwined that it becomes difficult to tell whose money is whose, making it extremely complicated and costly to ever separate. The accumulated estate serves as a bond and makes it impossible to break up in the heat of the moment" (Blumstein and Schwartz 1983).

In the current study the respondents were asked twenty questions to try and shed some light on whether or not these long-term couples had created such "entanglements" for themselves, and at what point during their relationship they had done this. Specifically, I wanted to know if the couples had created these bonds early in their relationships, possibly supporting the argument that the structural supports facilitated their current longevity.

${ }^{7}$ Caldwell and Peplau thought that perhaps their sample was too feminist to make any meaningful correlations. 
The results are somewhat vague and open to interpretation. Just over half of the respondents had joint savings accounts, and sixty percent had joint checking accounts. Only a third had power of attorney for one another and only half had wills. Approximately ten percent of the sample had, within the first two years, created power of attorney for one another or set up their partner as beneficiary of their will (see Table 11). The rest acquired these over time.

A slightly higher percentage of the couples had ties from purchases they had made together. Approximately seventy-five percent had bought furniture, appliances and/or cars together. Of those, about half bought them during their first four years together. Sixty percent had bought a home together, and a third of them had done so within their first four years. Almost all of the respondents pooled at least enough money to meet expenses, although only sixty percent pooled all of their money. ${ }^{8}$ In paying for their expenses, approximately a third paid equally, more than a third didn't keep track, and a quarter paid in proportion to their income.

Overall, only about twenty percent of this sample created the "structural supports" within their first few years together. Eventually, however, two thirds of these couples did acquire most of these financial bonds.

${ }^{8}$ This percentage of lesbian respondents who pool their money is similar to that found by Blumstein and Schwartz (1983) 
Table 11

"STRUCTURAL SUPPORTS" BY YEAR IN RELATIONSHIP ACQUIRED, BY PERCENT

$(\mathrm{N}=105)$

\begin{tabular}{|c|c|c|c|c|}
\hline & YES & Year 1-2 & $\begin{array}{l}\text { Year 3- } \\
5\end{array}$ & Year 5+ \\
\hline $\begin{array}{l}\text { Have joint } \\
\text { savings }\end{array}$ & 54.3 & 26.7 & 13.3 & 14.3 \\
\hline $\begin{array}{l}\text { Have joint } \\
\text { checking }\end{array}$ & 59.0 & 37.2 & 12.4 & 11.4 \\
\hline $\begin{array}{l}\text { Have power } \\
\text { of attorney }\end{array}$ & 33.4 & 6.7 & 14.3 & 12.4 \\
\hline Have wills & 46.7 & & & \\
\hline $\begin{array}{l}\text { Have wills } \\
\text { partner } \\
\text { beneficiary }\end{array}$ & 41.9 & 13.3 & 16.2 & 12.4 \\
\hline $\begin{array}{l}\text { Major } \\
\text { purchases } \\
\text { together }\end{array}$ & 92.4 & & & \\
\hline $\begin{array}{l}\text { Bought a } \\
\text { car together }\end{array}$ & 62.0 & 29.6 & 20.9 & 11.5 \\
\hline $\begin{array}{l}\text { Bought a } \\
\text { home } \\
\text { together }\end{array}$ & 61.1 & 13.4 & 26.7 & 21.0 \\
\hline $\begin{array}{l}\text { Pool all } \\
\text { their money }\end{array}$ & 59.1 & & & \\
\hline
\end{tabular}




\section{$\underline{\text { Sexuality }}$}

It has been noted that the frequency of sex declines the longer a couple stays together, and to some extent, with age (Blumstein and Schwartz, 1983; McWhirter, Mattison 1984; Peplau et al. 1978). This study confirms those findings. The respondents in this study were also more likely than those from an earlier study (Peplau et al. 1978) to say that they wanted to have sex more often, and slightly less likely to say that they found sex "extremely" satisfying. The respondents in this current study were, however, slightly more likely to "always" or "almost always" experience orgasm with their partner. ${ }^{9}$

Several other findings which differed from earlier studies (Blumstein and Schwartz 1983, Gordon 1980, Loulan 1987) may also be longevity-related. For example, in earlier studies (Blumstein and Schwartz 1983; Gordon, 1980), only sixty percent and seventy percent respectively of their samples had an implicit or explicit agreement to be monogamous. Of the current respondents nearly eighty percent had such an agreement. In that same study the women were asked if they would leave their relationship it they stopped having sex altogether. Seventy percent of those respondents, compared to eighty-four percent of the current study said they would not leave.

The most surprising finding was that women who scored higher in fusion were reporting having sex once to twice a week, twice as frequently as those who scored low on fusion. This is not at all what was indicated in prior research and in general understandings of the psychological nature of enmeshment (Krestan and Bepko, 1980; 
Krieger, 1983; Lindenbaum,1981). However, they were also twice as likely to be having sex only occasionally or not at all (see Table 12). The effects of societal prejudice and pressures on lesbian sexuality have not been established, however, in the current study of those women reporting having sex less than once every six weeks or not at all, seventy percent were not "out" at all at school or work.

Table 12

SEXUAL FREQUENCY BY LEVELS OF FUSION,$^{10}$

BY PERCENTAGE

$(\mathrm{N}=105)$

\begin{tabular}{||l|c|c||}
\hline Sexual Frequency & High Fusion & Low Fusion \\
\hline 1-2 times a week & 38.5 & 18.5 \\
\hline 1-2 times a month & 26.9 & 51.9 \\
\hline less than once a month & 16.7 & 22.2 \\
\hline less than twice a year & 12.8 & 3.7 \\
\hline not at all & 3.8 & 3.7 \\
\hline not at all & $100 \%$ & $100 \%$ \\
\hline
\end{tabular}

Other findings in this study replicated those of earlier research (Blumstein and Schwartz 1983; Loulan 1987; Peplau and Cochran 1987;). For example, those reporting higher autonomy were more likely to have been non-monogamous in their relationship (see Table 13). Generally, the couples in this study reported sexual frequency similar to that found in earlier studies, with approximately a third of the sample reporting having sex once to twice a week, a third, once to twice a month, and a third reporting having sex less than once a month. Nearly all of the respondents had had partners before their current relationship. In findings similar to those of Caldwell

\footnotetext{
${ }^{10}$ This table was created using the second fusion scale. However the percentages were very similar for the initial scale as well.
} 
and Peplau's (1984), eighty-four percent of the current sample had had prior relationships with men, and most (87\%) had prior relationship(s) with women.

Table 13

NON-MONOGAMY, BY AUTONOMY, BY PERCENTAGE

$(\mathrm{N}=105)$

\begin{tabular}{|l|l|l|}
\hline & $\begin{array}{l}\text { Lower } \\
\text { Autonomy }\end{array}$ & $\begin{array}{l}\text { Higher } \\
\text { Autonomy }\end{array}$ \\
\hline Have been non-monogamous & 14.3 & 30.6 \\
\hline Have not been non-monogamous & 85.7 & 67.3 \\
\hline
\end{tabular}

Similar to previous studies, the current findings reveal the importance of equality in relationships to lesbians. Likewise, the lesbians in this study were found to highly value feminism, to value both autonomy and relatedness, and to create commitment over time. They were as likely as those in previous studies to be sexually satisfied. However, the lesbians in the current study felt more equal in their relationships, were more committed to their partner, and more willing to make sacrifices for the relationship than were lesbians in prior studies. 


\section{CHAPTER V}

\section{CONCLUSION}

This study was undertaken to identify the relational dynamics of lesbians in long-term relationships and to compare these findings with those identified in earlier research done with lesbians in shorter-term or term non-specific relationships. The initial assumption was that just as research has found relational differences between heterosexual couples who live together and those who are married, so to would lesbian relational dynamics differ among couples of varying commitment levels. As lesbians do not have an obvious marker of commitment such as marriage, I chose longevity as the marker of commitment.

\section{Power and Equality}

In making comparisons between the current and previous studies, I looked first at how lesbians handled the issue of power dynamics. Earlier research had indicated that lesbians were extremely sensitive to any power imbalances in their relationships. In many studies it was listed as a primary reason why couples broke up.

One of my initial suppositions was that if lesbians had such difficulty with inequality, and often broke up because of it, then a lesbian relationship that was able to last would mostly likely have to have a real or perceived equal balance of power. In this study, lesbians generally did feel more equal in their relationships and more committed to them than respondents in earlier research. 
There was a substantial difference between the percentage of respondents who felt that their relationship was generally "exactly equal" (85\%) and those that answered "exactly equal" on specific questions regarding power (approximately 60\%). There are be several possible explanations for this discrepancy. One explanation may be that the respondents do not necessarily feel "exactly equal" in every single aspect of their relationship but find equality in specific areas, allowing them to feel "exactly equal" in an overall sense (most of the responses that were not "exactly equal" were "close to equal"). Another explanation may be the difference between a personal value that is reflected in the more general question and the realities that must be confronted in the specific questions.

The distinction between a real balance of power and a perceived balance of power is important to note. Since equality is so ideologically important to lesbians, they might choose not to notice the ways in which their relationships are unequal, as the perception of inequality could have serious consequences for them. However, since participants in earlier studies and in the current one were likely to have had a similar investment in the perception of equality, the conclusion that lesbians in longerterm relationships may have resolved their power imbalances through time or perhaps had a more balanced relationship initially seems reasonable.

Social exchange theory predicts that the person who is the least committed to the relationship will have the most power. However, in the current study almost all of the respondents felt that their relationship had an equal or nearly equal balance of power, and a high level of commitment. If one assumes that longevity may be by itself some measure of satisfaction, then this would seem to support Blau's statement that "the relative balance of involvement or commitment in a relationship affects satisfaction (and that) only when two lovers' affection for and commitment to 
one another expand at roughly the same pace do they tend mutually to reinforce their love" (Blau 1964, p.84). It is perhaps not surprising then that in this study on longterm relationships, there are high levels of equality and commitment.

Social exchange theory may be less obviously relevant as a framework for understanding lesbian relationships than other kinds of relationships. While this theory predicts that power in a relationship will favor the partner who has the greater personal resources, it is often difficult to determine what those "resources" are for lesbians. In prior studies, differences in income and education have been found, at different times, to be both related and not related to differences in power. This current study again found them to be not related and supports the earlier finding that "lesbians do not use income to establish dominance. They use it to avoid having dominance" (Caldwell and Peplau 1984, p 595). Other studies have noted that physical beauty, which has been a "resource" for heterosexual and gay male couples, is a factor of lesser importance to lesbians, and less likely to be perceived as a "resource" that would affect the power balance (Blumstein and Schwartz 1983).

My assumption is that social exchange theory is still important for understanding lesbian relationships, but perhaps in a more subtle way. As was mentioned earlier, a resource can be "anything that one partner may make available to the other, helping the latter satisfy his [sic] needs or attain his goals" (Blood and Wolfe 1960, p.12). If lesbians are indeed made uncomfortable by obvious inequities, perhaps the "resources" that are made available might be more intangible, such as status in the community, social connections, skills and/or attributes that the partner wishes to acquire, or perhaps unique characteristics of the partner or partnership that feel irreplaceable. In retrospect, I would have liked to have asked the respondents directly what "resources" they felt their partner offered them. This would be a 
worthwhile subject for further investigation.

\section{Fusion and Enmeshment}

Another important issue in lesbian relational dynamics is that of psychological fusion or enmeshment. Earlier research has shown that many lesbians have difficulty maintaining personal boundaries within their relationship and that this inability creates difficulties that might result in termination of the relationship. Thus, I expected that the women in this study who had been in their relationship for some time, would not be experiencing fusion. In contrast to this expectation, the respondents reported high levels of fusion. I was equally surprised to find that, contrary to previous findings, women who were more highly fused were also more likely to be having sex frequently.

Those scoring higher in fusion were also more likely to be over forty and less feminist than those scoring lower in fusion. This may reflect a feminist emphasis on autonomy and perhaps the influence of feminism on those who encountered it during their younger years. Women's socialization has been changing rapidly and the possibilities for, as well as emphasis on, autonomy and independence are much greater now than they were even twenty years ago. Many of the studies that examined lesbians' problems with enmeshment are now fifteen to twenty years old, and in the subsequent years the women's and gay rights movements have allowed women greater access to personal autonomy as well as freedom to be "out". Since lesbian fusion is so closely tied to women's socialization and heterosexist constraints, changes in either of those are bound to directly affect fusion dynamics. Fusion was related to "outness". Those higher in fusion were less likely to be "out". This would support the assumption by many (Burch 1985; Elise 1986; Falco 1991) that the pressures of being gay in a heterosexist culture may cause lesbians to turn inward towards a 
partner.

Fusion, as noted earlier, is a difficult phenomenon to study. Because they involve two women, lesbian relationships have different dynamics than heterosexual relationships. In the current study lesbians did seem to experience fusion and yet this did not seem to affect either the longevity or sexuality of their relationship. There seems to be a fine line between the assets and costs of lesbian fusion. As noted by Falco (1991, p.72), "lesbian relationships are often closer than other coupled relationships. This is a natural and even predictable outcome of women's desire and capacity for emotional connection." The cost is often a lack of autonomy. Perhaps the women in this study were able to balance the two in a way not obviously revealed in the questionnaire responses. Perhaps future research could look in greater depth at this issue.

\section{$\underline{\text { Feminism }}$}

Some early researchers speculated that a feminist emphasis on autonomy and independence might make longevity difficult for lesbians. Both the previous studies and current study do show high value on feminist ideology among lesbians, and yet this study indicates that feminism does not have a negative effect on lesbians' ability to have relational longevity. Autonomous capacity, stressed by feminism, seems to be the balancing mechanism for women's tendency towards greater relational emphasis; it may mean that women can value the quality of their relationships and allow themselves the personal strength to stay in a relationship out of choice rather than because of emotional or financial dependence. The lesbians in the current study have been able to incorporate feminism, autonomy, commitment, high satisfaction and duration. And, importantly, the more feminist the women were, the more likely they 
were to be in an equal relationship.

Feminism's emphasis on having the choice of non-monogamy also seems not to have affected the relational longevity of the lesbians in the current study. While most of these women and those lesbians in earlier relational studies favored personal choice regarding an individual's decision to be sexual with whomever they chose, most also practiced monogamy.

\section{$\underline{\text { Sexuality }}$}

There were few surprises found in this study in the area of sexuality. The majority of the women were having regular sex (though not quite as frequently as those in shorter term relationships), were quite satisfied with the quality if not the quantity of sex in their lives, and were monogamous. The only surprising find was that more highly fused women were twice as likely to be having sex once a week or more than women who were less fused. This is contrary to what the literature to date indicates. They were also the group more likely to be having sex less than twice a year or not at all, but that was expected.

The difference between levels of intimacy that "fan the flames" and those that smother may be difficult to uncover. If personal autonomy is the key that allows lesbians to successfully manage high levels of intimacy (or the capacity for, and legitimacy of it), then perhaps the high sexual frequencies indicate that some of these women have successfully integrated independence and merger. As Lindenbaum (1985, p.87) notes: "mature intimacy requires that the partners move comfortably between more merged and more differentiated relational positions." 


\section{Structural Support}

Blumstein and Schwartz speculated that if gay couples created for themselves structural supports that tend to come more automatically for heterosexual married couples, it might aid the attempt by gay couples to build more durable relationships. They theorized that structural supports act as an anchor for couples as they hit periodic disturbance. Gay couples who do not have the benefit of the legally supportive marriage license or societal support to help them through the difficult times might attempt to create their own support.

In the current study most of the couples had financial but not legal bonds. More than half had joint savings, joint checking accounts, pooled their money or bought a home and/or car together. A sizeable number of these couples did this in the first two years of their relationship, possibly adding credence to the Blumstein and Schwartz contention. But in lesbian relationships, because their is no formal marker of commitment, trust in the future of the relationship usually comes gradually with time (Blumstein and Schwartz 1983). A couple's willingness to create such financial bonds so early in their relationship might be more indicative of the high level of commitment with which they began the relationship than of the way in which structural supports facilitate relationship longevity.

However, most of those who had financial commitments did acquire them later in their relationship, assumably as their faith in its future solidified. Possibly those bonds did help them stay together. But what helped them stay together the first three to five years? Approximately forty percent of the couples never pooled their money, bought a home or car together, or had joint checking or savings, and yet they too had a long-term relationship.

Without a longitudinal study it is hard to know conclusively the effects of 
structural supports for the lesbian couple. The results of the current study tend to muddy rather than illuminate the issue as I had hoped.

Concluding this study, I find that there are many things I would do differently now. I would have liked to have more completely examined fusion, and I would have changed the questions I used to measure fusion. I have strong suspicions that respondents may have answered statements like "there are times when I am with my friends and I do not want my partner along" with a variable rather than a definitive answer. I wanted to know if the statement was ever true for the respondents and I suspect they may have answered how often it was true for them. I was trying to determine if separateness was allowed in the relationship. I am concerned that, because of lack of questionnaire clarity, the answers were not a true reflection of the respondent's beliefs. Future research might examine this issue further.

I would also like to have come up with a better measure of feminism than asking the respondents how important feminism was to them. I had initially hoped to create a scale using four questions to measure feminism but none of the questions seemed as accurate a reflection of feminism as I had hoped for.

In the section on power and equality I would have liked to have asked more detailed questions about how the respondents felt about equality and what measures they had taken (if any) to balance inequities. In retrospect, the questions I asked seem very broad and likely to reflect ideals perhaps more than reality.

Many of the findings in the current study were similar to those of researchers who had done earlier work. Lesbian relationships appear to have a number of similarities to one another across length of time together. The respondents were just as likely as those in prior studies to be feminists, to value both autonomy and relatedness, to be sexually satisfied, and to have similar attitudes about women's 
issues. But the differences are also important to note. Lesbians couples in this study were more equal, more committed, more likely to have joint acquisitions and/or pooled finances, and more likely to make sacrifices for the relationship. Lesbians who value long-term commitments may find this information helpful in their quest to create such a relationship.

For researchers examining relational dynamics and comparing married couples with gay and lesbian couples, these differences are especially important to note. Most married couples are, de facto, more likely to have a higher initial level of commitment, rooted in a legal contract, whereas gay couples typically solidify commitment in an evolutionary process over time. Duration, therefore, is a variable of considerable importance whenever studying lesbians, and should be included in future research. 


\section{$\underline{\text { Bibliography }}$}

Abbot,S. and Love,B. 1972 Sappho Was a Right on Women: A Liberated View of Lesbianism. New York: Stein and Day

Barnhart,E. 1975 Friends And Lovers In A Lesbian Counterculture Community in N. Glazer-Malbin (Ed.), Old Family/New Family. New York: Van Nostrand

Blau,P.M. 1964 Exchange and Power in Social Life. New York: Wiley, 1964

Blood,R.O., and Wolf, D.M. 1960 Husbands and Wives: The Dynamics Of Family Living. Glenco, Illinois: Free Press

Blumstein,P. Schwartz,P. 1983 American Couples. New York:Pocket Books

Burch,B. 1985 "Another Perspective on Merger in Lesbian Relationships" in L.B. Rosewater and L. Walker (Eds.), Handbook of Feminist Therapy: Womens Issues in Psychotherapy: New York, 100-109

Burch,B. 1982 "Psychological Merger in Lesbian Couples: A Joint Ego Psychological and Systems Approach" in Family Therapy, Fall

Caldwell,M. and Peplau,L. 1984 "The Balance of Power in Lesbian Relationships" Sex Roles, 10:587-599

Choderow,N. 1978 The Reproduction of Mothering: Psychoanalysis and the Sociology of Gender. Berkeley: University of California Press

Cotton,W. 1975 "Social and Sexual Relationships of Lesbians" in The Journal of Sex Research, 11:139-148

Dahlstrom,S. 1989 "Sex Role Traits and Psychological Merger in Lesbian Relationships". Unpublished Master's Thesis, Portland State University

Dinnerstein,D. 1976 The Mermaid and the Minotaur: Sexual Arrangements and Human Malaise, New York: Harper and Row

Elise,D. 1986 "Lesbian Couples: The Implications of Sex Differences in SeparationIndividuation" Psychotherapy, 23:305-310

Falbo,T. and Peplau,L.A., 1980 "Power strategies in Intimate Relationships" in Journal of Personality and Social Psychology, 38:818-628

Ferguson,K.D. and Finkler,D. 1978 "An Involvement and Overtness Measure for Lesbians: Its Development and Relation to Anxiety and Social Zeitgeist" Archives of Sexual Behavior, 7:211-227

Gilligan,C. 1982 In a Different Voice: Psychological Theory and Women's

Development. Cambridge: Harvard University Press 
Gordon,K. 1980 "Norms of Thriving Lesbian Relationships. Unpublished Masters Thesis, University of Oregon School of Nursing

Hedblom,J. 1973 "Dimensions of Lesbian Sexual Experience" in Archives of Sexual Behavior, 2:329-341

Heibrun,A.B., and Thompson,N.L. 1977 "Sex Role Identity and Male and Female Homosexuality" Sex Roles, 3:65-79

Karpel,M. 1976 "Individuation: From Fusion to Dialogue" Family Process, 15:65-82.

Krestan,J. and Bepko,C. 1980 "The Problem of Fusion in the Lesbian Relationship" Family Process, 19:277-290

Kurdek,L. and Schmitt,P. 1986 "Early Development of Relationship Quality in Heterosexual Married, Heterosexual Cohabitation, Gay, and Lesbian Couples" Developmental Psychology, 22:305-309

Kurdek,L. and Schmitt,P. 1986 "Interaction of Sex Role Self-Concept with Relationship Quality and Relationship Beliefs in Married, Heterosexual Cohabiting, Gay and Lesbian Couples" Journal of Personality and Social Psychology, 51:365-370

Laner,M. 1977 "Permanent Partner Priorities: Gay and Straight" Journal of Homosexuality, 3:20-39

Lindenbaum,T. 1981 "Understanding the Lesbian Couple: An Object-Relations Systems Approach." Paper presented at Annual Meeting of the American Orthopsychiatric Association, New York

Loewenstein,S. 1980 "Understanding Lesbian Women" Social Casework,1:29-38

Loulan,J. 1987 The Passion of Lesbian Sex. Berkely, CA: Spinster/Aunt Lute

Peplau,L.A. and Cochran.S.D. 1987 "A Relationship Perspective on Homosexuality" Unpublished manuscript, California State University, Northridge

Peplau,L.A. 1983 "Role and Gender" in H.H. Kelley, E. Berscheid, A. Christensen, H.H. Harvey, T. L. Huston, G. Levinger, E. McCLintock, L.A. Peplau, and D.R. Peterson,(Eds.) Close Relationships, San Francisco, Freeman 28-38

Peplau,L.A. and Amaro,H. 1983 "Understanding Lesbian Relationships" in W. Paul and J.D. Weinrich (Eds.), Homosexuality As A Social Issue. Beverly Hills, CA: Sage Publications

Peplau,L.A., Pedasky,C.,Hamilton,M. 1982 "Satisfaction in Lesbian Relationships", Journal of Homosexuality, 23-35 
Peplau,L.,Cochran,S.,Rook,K.,Padesky,C. 1978 "Loving Women: Attachment and Autonomy in Lesbian Relationships" Journal of Social Issues, 34:7-27

Rubin,L. 1983 Intimate Strangers. New york: Harper and Row

Rusbult,C.E. 1983 "A Longitudinal Test of the Investment Model". Journal of Personality and Social Psychology, 45:104-117

Schneider,M. 1986 "The Relationships of Cohabitating Lesbian and Heterosexual Couples: A Comparison" in Psychology of Women Quarterly, 10:234-239

Smalley,S. 1987 "Dependency Issues in Lesbian Relationships" in Journal of Homosexuality, 14:12-136

Tuller,N. 1978 "Couples: the Hidden Segment of the Gay World" in Journal of Homosexuality, 3:331-343

Tripp,C.A. 1975 The Homosexual Matrix, New York: McGraw Hill

Waller,W. 1938 The Family: A Dynamic Interpretation, New York: Gordon

Weber,J. 19979 "Lesbian Networks" Christopher Street, 3:51-54 
APPENDIX 
Please answer all questions on BOTH sides of the paper. Place the correct number of your answer on the blank provided on the left. All questionnaires are anonymous.

1. Age 1. under 21

2. $21-30$

3. $31-40$

4. $41-50$

5. $51-60$

6. over 60

2. Race

1. Caucasian

2. Black

3. Hispanic

4. Asian

5. Native American

6. Puerto Rican

7. Other (list)

3. Education - Circle the highest grade you have achieved

$$
\begin{array}{lllllllllllllllll}
1 & 2 & 3 & 4 & 5 & 6 & 7 & 8 & 9 & 10 & 1 & 12 & 13 & 14 & 15 & 16 & 17
\end{array}
$$

4. Do you have a college degree?

1. No

2. Yes, Bachelor's

3. Yes, Master's

4. Yes, Ph.D.

5. Other (list)

5. Occupation

1. Laborers

2. Professional and technical

3. Clerical and related

4. Student

5. Sales

6. Managers and administrators

7. Other (specify)

6. Income (yours)

1. Below $\$ 5,000$ p/year

2. $\$ 5,000-\$ 14,000$

3. $\$ 15,000-\$ 24,000$

4. $\$ 25,000-\$ 34,000$

5. $\$ 35,000-\$ 44,000$

6. $\$ 45,000-\$ 54,000$

7. $\$ 55,000$ or more 
7. Joint Income (yours and your partners)
1. Below $\$ 5,000$ p/year
2. $\$ 5,000-\$ 14,000$
3. $\$ 15,000-\$ 24,000$
4. $\$ 25,000-\$ 34,000$
5. $\$ 35,000-\$ 44,000$
6. $\$ 45,000-\$ 54,000$
7. $\$ 55,000$ or more

8. What is your current religious preference?
1. No religious preference
2. Protestant (Specify denomination)
3. Catholic
4. Jewish
5. Other (specify)

9. About how often do you attend church, synagogue, or other worship?
1. Once a week or more
2. One to three times a month
3. Several times a year
4. Once a year or less
5. Seldom
6. Never

10. Overall, how religious would you say you are?
1. Very
2. Somewhat
3. A little
4. Not very
5. Not at all

11. How would you describe your political outlook?

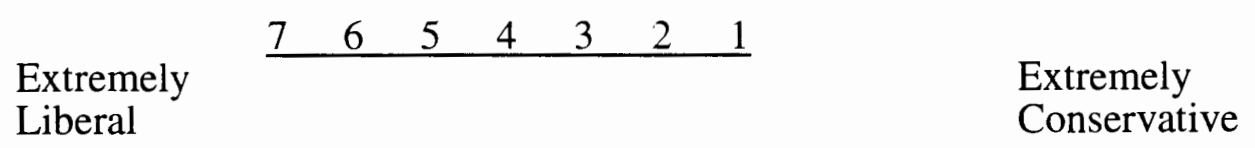

12. There are times when I am with my friends and I do not want my partner along.

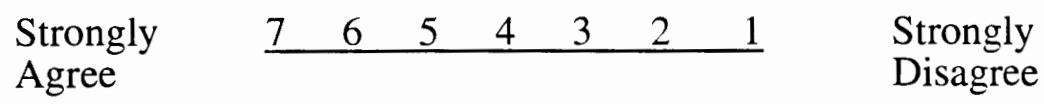

13. It is important to me that my partner spend some time without me.
Strongly
\begin{tabular}{lllllll}
7 & 6 & 5 & 4 & 3 & 2 & 1 \\
\hline
\end{tabular}
Strongly
Agree
Disagree 
14. It is important to me that my partner and I spend all of our free time together.

Strongly

Agree

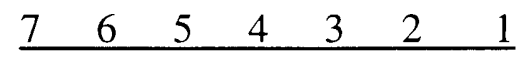

1
Strongly

Disagree

15. It is important to me that my partner and I each have some interests, activities, and friends that we pursue without the other.

$\begin{array}{lllllllll}\begin{array}{l}\text { Strongly } \\ \text { Agree }\end{array} & 7 & 6 & 5 & 4 & 3 & 2 & 1 & \begin{array}{l}\text { Strongly } \\ \text { Disagree }\end{array}\end{array}$

16. Do you consider yourself to be a feminist?

Yes, Very $\begin{array}{lllllllll}7 & 6 & 5 & 4 & 3 & 2 & 1 & \text { No, not at all }\end{array}$

17. How important is feminism to you?

$$
\text { Very } \begin{array}{lllllll}
7 & 6 & 5 & 4 & 3 & 2 & 1
\end{array} \text { not at all }
$$

18. How involved are you in feminist activities?

$$
\text { Very } \begin{array}{llllllll}
7 & 6 & 5 & 4 & 3 & 2 & 1
\end{array} \text { not at all }
$$

19. How much do you read feminist materials (books, magazines, etc.)?

Often $\begin{array}{lllllll}7 & 6 & 5 & 4 & 3 & 2 & 1\end{array}$ Not at all

20. Do you and your partner have power of attorney papers for each other?

1. Yes, I do for her

2. Yes, she does for me

3. No

21. If yes, during which year of your relationship did you do this?

1. first

2. second

3. third

4. fourth

5. fifth

6. after the fifth year

22. Do you have a will?

1. Yes

2. No

23. If yes, is your partner the major beneficiary?

1. Yes

2. No 
24. If yes, during which year of your relationship did you designate your partner as the major beneficiary?
1. first
2. second
3. third
4. fourth
5. fifth
6. after the fifth

25. Do you and your partner have a joint checking account?
1. Yes
2. No

26. If yes, during which year of your relationship did you do this?
1. first
2. second
3. third
4. fourth
5. fifth
6. after the fifth

27. If yes, do you also have an individual checking account?
1. Only I do
2. Only my partner does
3. Both of us do
4. Neither of us do

28. Do you and your partner have joint savings account?
1. Yes
2. No

29. If yes, during which year of your relationship did you open this account?
1. first
2. second
3. third
4. fourth
5. fifth
6. after the fifth 
30. If yes, do you also have an individual savings account?
1. Only I do
2. Only my partner does
3. Both of us do
4. Neither of us do

31. Which of the following best describes how you and your partner handle your finances?

1. We pool all of our incomes

2. We pool most, but not all of our incomes

3. We pool only enough of our incomes to pay expense

4. We pool a small amount of our incomes

5. We pool none of our incomes

32. How do you and your partner pay for joint expenses?

1. We both pay equally

2. We pay proportionately to our incomes

3. One partner pays all of the expense

4. We do not keep track

5. Whoever has money at the time

33. If you and your partner have made major purchases together in your relationship, please mark the appropriate purchases, and write in during what year of your relationship they were made.

$\begin{array}{ll}\text { Auto__} & \text { Year } \\ \text { Home } & \text { Year__ } \\ \text { Furniture } & \text { Year_} \\ \text { Appliances__ } & \text { Year } \\ \text { Other } & \text { Year }\end{array}$

34. If you have not already, would you be willing to buy a home with your partner?

1. Yes

2. No

3. Maybe

35. Would you be willing to support your partner financially if necessary?

1. Yes

2. No 
36. Should your partner need to relocate for an attractive job or school opportunity, would you be willing to move with her?

1. yes, definitely

2. Yes, probably

3. Probably not

4. No

37. How certain are you that your relationship will last for six months?

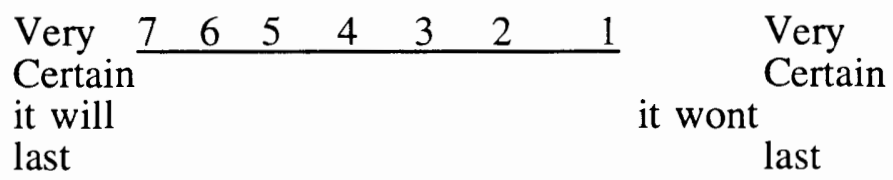

38. last for 1 year?

39. last for 5 years?

40. How important is it to you that this relationship be permanent?
1. Extremely important
2. Quite important
3. Somewhat important
4. Not very important
5. Not at all important

41. What is the age difference between you and your partner?

42. How many years have you and your partner been together?

43. Have you ever had a marriage ceremony, gay wedding, or holy union?

1. Yes

2. No

44. If no, do you plan to have one?

1. Yes

2. No

45. Do you perceive you and your partner to be a family?

1. Yes

2. No

46. Do you or your partner have children who reside with you?

1. Yes

2. No 
47. With how many men have you ever had sexual relations?
1. 0
2. 1
3. $2-5$
4. $6-10$
5. $11-20$
6. 21-50
7. $50+$

48. With how many women have you ever had sexual relations?
1. 0
2. 1
3. $2-5$
4. $6-10$
5. $11-20$
6. $21-50$
7. $50+$

49. How often do you experience orgasm with your partner?
1. Almost always
2. Usually
3. Occasionally
4. Rarely
5. Never

50. How satisfied are you with the sexual aspects of your relationship?

Very $\begin{array}{llllllll}7 & 6 & 5 & 4 & 3 & 2 & 1\end{array}$ not at all

51. How frequently do you and your partner have sex?
1. Four or more times a week
2. Once or twice a week
3 . Once or twice a month
4. Less than once a month
5. Less than once every six months
6 . We no longer have sex at all

52. Would you like to have sex more or less often?
1. More
2. Less
3. The same

53. If you and your partner stopped having sex altogether would you terminate the relationship. 
54. Before this relationship, did you ever live for over a month with someone with whom you were sexually involved?

55. If yes, how many times did you do this?

1. Once

2. Twice

3. Three times

4. Four times

5. Five to ten times

6. Ten or more times

56. In general, who has more say about important decisions affecting you and your partner?

I much more $\begin{array}{llllllll}7 & 6 & 5 & 4 & 3 & 2 & 1\end{array}$ She much more

57. Who do you think should have the final say about important decisions affecting you and your partner?

I much more $\begin{array}{lllllll}7 & 6 & 5 & 4 & 3 & 2 & 1\end{array}$ She much more

58. Who is more committed to the relationship, you or your partner?

I much more $\begin{array}{llllllll}7 & 6 & 5 & 4 & 3 & 2 & 1\end{array}$ She much more

59. Who has altered her habits and ways of doing things more to please the other?

I much more $\begin{array}{llllllll}7 & 6 & 5 & 4 & 3 & 2 & 1\end{array}$ She much more

60. Of you or your partner, who usually earns the most money?

I much more $\begin{array}{llllllll}7 & 6 & 5 & 4 & 3 & 2 & 1\end{array}$

61. Of you or your partner, who has the most formal education?

I much more $\begin{array}{lllllll}7 & 6 & 5 & 4 & 3 & 2 & 1\end{array}$ She much more

62. Who does the chores in your household?

I much more $\begin{array}{llllllll}7 & 6 & 5 & 4 & 3 & 2 & 1\end{array}$ She much more

63. Who usually has the most influence over how much time you spend with your partner?

I much more $\begin{array}{lllllll}7 & 6 & 5 & 4 & 3 & 2 & 1\end{array}$ She much more 
64. Who usually has the most influence over how much time you as a couple spend with other people?

I much more $\begin{array}{llllllll}7 & 6 & 5 & 4 & 3 & 2 & 1\end{array}$ She much more

65. To what extent do your partners parents make you feel like you are one of the family?

Her mother (put XX if it does not apply)

very much $\begin{array}{lllllll}7 & 6 & 5 & 4 & 3 & 2 & 1\end{array}$

66. Her Father (put XX if it does not apply)

very much $\begin{array}{lllllll}7 & 6 & 5 & 4 & 3 & 2 & 1\end{array}$ not at all

67. Who of your immediate family knows that you are part of a lesbian couple?

1. None of my immediate family

2. Some of my immediate family

3. All of my immediate family

68. Who of your extended family knows that you are part of a lesbian couple?

1. None of my extended family

2. Some of my extended family

3. Most of my extended family

69. If all, or some of your immediate family knows that you are a Lesbian, overall, how supportive would you say they are?

Very supportive $\begin{array}{rllllll}7 & 6 & 5 & 4 & 3 & 2 & 1\end{array}$ Not supportive at all

70. Do most of your friends know that you are a lesbian?

1. Yes

2. No

71. Does your doctor know that you are a lesbian?

1. Yes

2. No

72. How do you and your partner usually spend major holidays like Christmas, Thanksgiving and birthdays?

1. Together with family

2. Together without family

3. Apart with family 
73. Have differences in openness about being a lesbian caused you to have conflicts with your partner?

1. Yes

2. No

74. How "out" are you at work (or school if you are a student)?

1. Completely

2. Somewhat "out"

3. Not "out"

75. Would you like to spend more or less time with your partner?

1. More

2. Less

3. The same

76. Have you ever had sexual relations with anyone other than your current partner since you have been together? (This does not include time when you might have been "broken up".)

1. Yes
2. No

77. Which of the following best describes your and your partner's current understanding concerning sex outside of your relationship?

1. We have discussed it and decided that under some circumstance is all right.

2. We have discussed it and decided that under no circumstances is it all right.

3. We have discussed it and do not agree

4. We have not discussed it but I feel we would agree that under some circumstances it is all right.

5. We have not discussed it but I feel we would disagree.

78. Which of the following best describes your beliefs regarding monogamy?

1. Monogamy is essential for a successful relationship

2. Monogamy is not essential for a successful relationship

3. Monogamy is harmful to a successful relationship

79. At what age did you first suspect that you might be a lesbian. 
80. At what age was your first lesbian sexual experience?

Please rate on the scale of one to seven (seven being most important, one being least important) how important the following items are to you.

Most important \begin{tabular}{lllllll}
7 & 6 & 5 & 4 & 3 & 2 & 1 \\
\hline
\end{tabular}

81. sharing as many activities with my partner as possible

82. living together

83. spending as much time together as possible

84. knowing that the relationship will endure for a long time

85. sexual fidelity in the relationship

86. knowing that my partner depends on me

87. sexual compatibility

88. working together on tasks like shopping, cooking or cleaning, rather than dividing such tasks between us

89. having similar attitudes about womens issues

90. that we both have similar political attitudes

91. having a supportive group of friends as well as my partner

92. having an egalitarian(equal- power) relationship

93. being able to have sexual relations with people other than my partner

94. trying new sexual activities or techniques with my partner

95. enjoying our relationship now without insisting on a future commitment. 